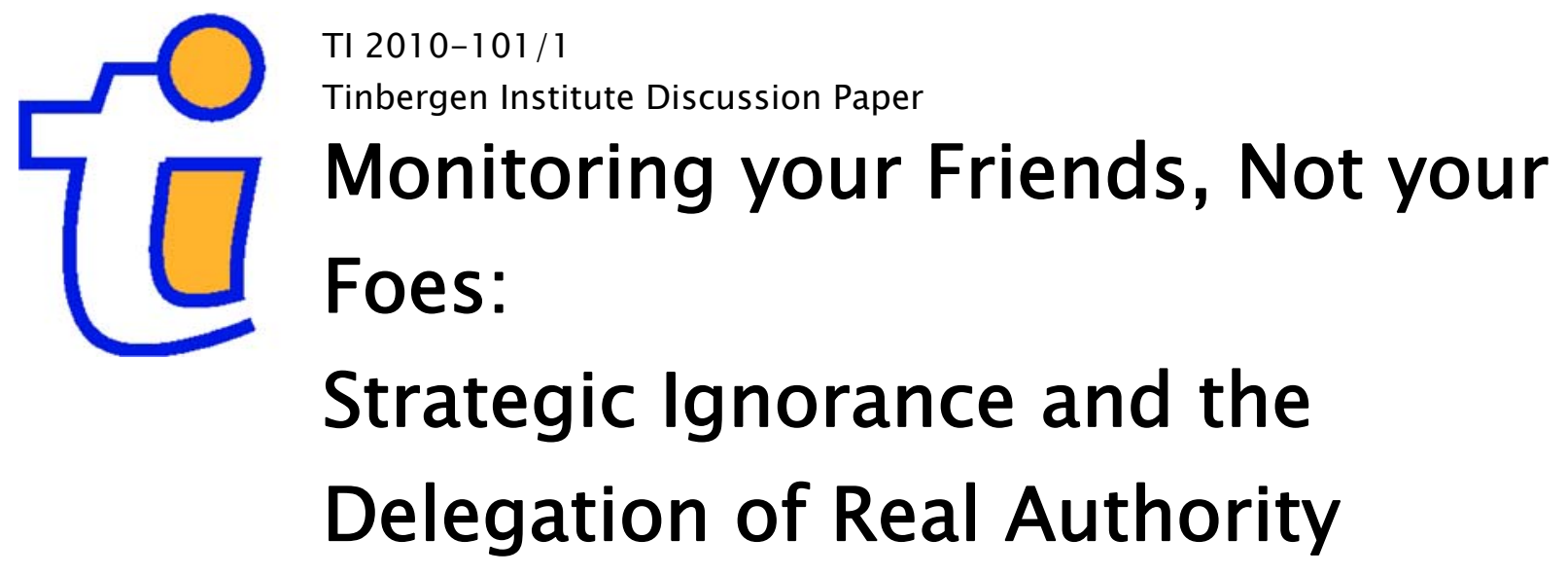

Silvia Dominguez-Martinez ${ }^{1,2}$

Randolph Sloof ,2

Ferdinand von Siemens ${ }^{1,3}$

1 University of Amsterdam;

2 Tinbergen Institute;

${ }_{3}$ CESifo. 


\section{Tinbergen Institute}

The Tinbergen Institute is the institute for economic research of the Erasmus Universiteit Rotterdam, Universiteit van Amsterdam, and Vrije Universiteit Amsterdam.

Tinbergen Institute Amsterdam

Roetersstraat 31

1018 WB Amsterdam

The Netherlands

Tel.: +31(0)205513500

Fax: $+31(0) 205513555$

Tinbergen Institute Rotterdam

Burg. Oudlaan 50

3062 PA Rotterdam

The Netherlands

Tel.: + $31(0) 104088900$

Fax: $+31(0) 104089031$

Most TI discussion papers can be downloaded at http://www.tinbergen.nl. 


\title{
Monitored By Your Friends, Not Your Foes: \\ Strategic Ignorance And The Delegation Of Real Authority*
}

\author{
Silvia Dominguez-Martinez \\ Randolph Sloof \\ Ferdinand von Siemens
}

December 2012

\begin{abstract}
In this laboratory experiment we study the use of strategic ignorance to delegate real authority within a firm. A worker can gather information on investment projects, while a manager makes the implementation decision. The manager can monitor the worker. This allows her to exploit any information gathered by the worker, but also reduces the worker's incentives to gather information in the first place. Both effects are influenced by the interest alignment between manager and worker. Our data confirm the prediction that optimal monitoring depends non-monotonically on the interest alignment between managers and workers. Managers also show some preferences for control that seem to be driven by loss aversion. We also find mild evidence for hidden benefits and costs of control. However, behavioral biases have only limited effects on organizational outcomes.
\end{abstract}

JEL: D20, D40, D63, D82, J30

Keywords: Delegation, Real Authority, Strategic Ignorance.

*The paper has been previously circulated under the title of "Monitoring your friends, not your foes: Strategic ignorance and the delegation of real authority." We are grateful to Tore Ellingsen, Joep Sonnemans, and Joël van der Weele for helpful comments. We thank the priority research area Behavioral Economics of the University of Amsterdam for financial support. Sloof and Dominguez-Martinez are members of the University of Amsterdam and the Tinbergen Institute. von Siemens is member of the Goethe University Frankfurt and CESifo. Corresponding author: Ferdinand von Siemens, Address: Faculty of Economics and Business Administration, Grueneburgplatz 1, 60323 Frankfurt am Main, Germany, Email: vonsiemens@econ.uni-frankfurt.de. 


\section{Introduction}

In a variety of strategic situations, more information may hurt an individual. The underlying intuition is that if it is commonly known that an individual gathers more information, this may change the behavior of other individuals. This change in behavior can be detrimental to the better informed individual. Consequently, rational individuals might stay ignorant for strategic reasons. One organizational issue where strategic ignorance is likely to play an important role is the effective delegation of decision rights. This argument is developed in a pioneering contribution by Aghion and Tirole (1997) and explored further in Baker, Gibbons, and Murphy (1999). In Aghion and Tirole a worker fears to be overruled by his manager if the latter is well-informed about the consequences of some operational decisions. This fear thwarts the worker's incentives to gather information. An uninformed manager can credibly commit not to overrule, since she does not know the most appropriate operational decision. Realizing that his preferred decision will be implemented, the worker has stronger incentives to gather information. Strategic ignorance can thus be a crucial tool to delegate effective control over decisions - called real authority - to lower level employees.

The argument is compelling from a theoretical point of view, yet empirical evidence on the underlying strategic mechanism is scarce. Moreover, practitioners, the popular business press, and many studies on monetary incentives and control indeed suggest that Aghion and Tirole might ignore important behavioral biases of both managers and workers.

Regarding managers, anecdotal evidence paints the picture that many individuals are overly reluctant to delegate decision rights. The negative consequence of such preferences for control are reflected in management advice like Manzoni and Barsoux (1998) and Herzberg (2003). Rather than emphasizing the perils of lost control, this management literature warns for the negative consequences of "micromanagement." The problem of excess centralization has been discussed at least since Williamson (1996, pp.150-151) who comments on the connection between managerial meddling and selective intervention by arguing that "... the option to intervene can be exercised both for good cause and for bad." And in a recent case study Foss (2003) illustrates the disastrous consequences of managerial meddling on subordinates motivation. Individual managers with behavioral preferences for control might thus be less willing to delegate real authority than suggested by Aghion and Tirole (1997) and Baker, Gibbons, and Murphy (1999). This could reduce organizational efficiency by completely eroding subordinates' incentives to gather information. 
Besides managers' control preferences, the negative incentive effects of exerting control could be amplified by workers' behavioral biases. Falk and Kosfeld (2006) show that tightening control can reduce worker performance by eroding the willingness to cooperate. This is consistent with studies in psychology and organizational economics, where recent explanations for hidden costs of control and motivational crowding out have been put forward by Bénabou and Tirole (2003), Sliwka (2007), and Ellingsen and Johannesson (2008). ${ }^{1}$ With hidden costs of control, centralization could be even more detrimental to subordinates' motivation than suggested by Aghion and Tirole (1997) and Baker, Gibbons, and Murphy (1999). Combined with managers' preferences for control, this has the potential to greatly reduce organizational efficiency.

To study whether the above biases of managers and workers influence the allocation of decision rights within organizations, we empirically investigate strategic ignorance and the delegation of real authority in a controlled laboratory environment. Our experiment builds on a model close to Aghion and Tirole (1997). A manager hires a worker to screen investment projects. The manager first decides whether or not to monitor her worker at some costs. The worker observes the manager's monitoring decision and then decides whether to gather costly information on the projects. If the worker collects information, he learns the payoffs of each of the projects. Otherwise he does not learn anything. No matter whether the worker is informed or not, he next recommends a project to the manager. She observes whether the worker has gathered information and also learns his recommendation. The manager finally decides which project to implement. In the latter we follow Baker, Gibbons, and Murphy (1999, p.56) who take “... all subordinates' decision rights as loaned, not owned." Formal delegation of decision authority is therefore not possible.

Monitoring implies that the manager gets access to the same information the worker has. The manager thus becomes fully informed on all projects if the worker gathers information and remains uninformed otherwise. If the manager does not monitor, she only obtains information on the worker's recommended project. We consider two variations in our experiment: under "hard information" the manager can verify any information presented by the worker. She then learns the payoffs associated with the recommended project if the worker gathered information. Under "soft information" the manager never learns the payoffs of any project,

\footnotetext{
${ }^{1}$ See also Barkema (1995), Ariely, Kamenica, and Prelec (2008), and Dickinson and Villeval (2008). Frey and Jegen (2001) provide extensive surveys of the empirical evidence. We will further discuss the connection of our study to social psychology after presenting our empirical results (see Subsection 8.2).
} 
but just sees which project is recommended. We discuss below how this variation allows us to study whether loss aversion might drive any observed excess monitoring.

Parameters are chosen such that the manager is best off in money terms if she follows the worker's recommendation to implement his most preferred project, instead of choosing one of the other projects in the dark. Our design thus captures the observation by Aghion and Tirole (1997) that the manager's monitoring decision is governed by two opposing forces. On the one hand, if the worker gathers information, then monitoring allows the manager to push through her most preferred project instead of the one preferred by the worker. On the other hand, monitoring reduces the worker's incentives to gather information as he realizes that he will be overruled. The strength of the effects, and thus equilibrium behavior if individuals maximize expected payoffs, depends on the interest alignment between manager and worker. In our experiment we consider three different cases. Under "full interest alignment" the manager does not monitor since an informed worker recommends the project that is preferred by both. Under "strong interest alignment" the manager monitors since she can implement her most preferred project without destroying the worker's incentives to gather information. Under "weak interest alignment" the manager does not monitor as this discourages the worker's information gathering.

With our experiment we test this predicted non-monotonic relationship between monitoring and interest alignment. Yet we can also use our setup to study behavioral biases of managers and workers. Several behavioral forces could drive excess monitoring and thus too little delegation, both in our experiment and in real organizations. First, individuals might derive intrinsic utility from authority. This is consistent with the evidence from Herz, Bartling, and Fehr (2011) and Owens, Grossman, and Fackler (2012). Individuals with pure preferences for control might obviously keep too much control, even if this reduces their monetary payoffs. Second, individuals might be intrinsically motivated to gather information. Loewenstein (1994) summarizes and reinterprets the substantial psychological research on curiosity. Camerer, Loewenstein, and Weber (1989) document that additional information can hurt success, while Loewenstein, Moore, and Weber (2006) suggest that individuals might be willing to pay for such harmful information. This resonates with Feldman and March (1981) who argue that organizations often collect information that is not effectively used in any decision process. Individuals with preferences for information might find it hard to sustain strategic ignorance, resulting in too little effective delegation. 
We do not question that individuals might have pure preferences for control or information, yet in our paper we focus on loss aversion in the spirit of Köszegi and Rabin (2006) as another potential driver of excess monitoring. Their theory allows us to formalize the following intuition. Delegation leads to a loss of control especially if workers do not behave in a fully rational and predictable manner. With some probability loss of control then results in low payoffs for managers. Loss averse managers suffer strongly from improbable losses. We show that such managers might keep control, even if this reduces expected monetary payoffs. The reason is that keeping control allows them to intervene in the improbable case that workers misbehave.

Intuition suggests that loss aversion always promotes keeping control. However, our analysis reveals that loss aversion can also diminish incentives to monitor. This result is driven by an important component of Köszegi and Rabin: reference points and thus the weights of reference payoffs are endogenous. There are two implications. First, managers take into account that monitoring can discourage information gathering by some workers. This renders reference payoffs more stochastic, and thereby increases the suffering from expected losses. Second, monitoring can improve payoffs if workers are not discouraged to gather information. This increases reference payoffs and thus the reference point, which can increase expected relative losses. Loss aversion discourages monitoring via these two channels. This renders comparative statics with respect to interest alignment ambiguous. Fortunately, our formal analysis shows that loss aversion creates an unambiguous tendency towards more control if we deprive managers of seemingly irrelevant information. We build on this result in our design by varying whether information is hard or soft.

Our empirical results are as follows. Monitoring rates essentially follow the non-monotonic pattern as predicted by Aghion and Tirole (1997). In somewhat prosaic terms: workers are more likely to be monitored by their lukewarm friends than by their foes. The driving force here is that monitoring discourages information gathering in case preferences are weakly aligned. We also find some empirical evidence for behavioral biases. First, managers exhibit some preferences for control, where in particular monitoring rates are higher if information is soft rather than hard. But excess monitoring only persists under full interest alignment and soft information. This is consistent with our predictions based on Köszegi and Rabin (2006). Second, there are hidden benefits of control, since under full interest alignment monitoring unexpectedly increases information gathering by workers. Under strong interest alignment, monitoring slightly reduces information gathering even though it should have no impact. But 
this effect is not significant. Overall, behavioral biases have only limited consequences for organizational outcomes in our setup. We conclude that, despite recent findings from behavioral economics, Aghion and Tirole (1997) and Baker, Gibbons, and Murphy (1999) remain very useful frameworks to investigate the allocation of real authority within organizations.

We conclude this introduction by discussing related experiments. First, our experiment adds to the literature on strategic ignorance in bargaining contexts. Information on others' claims can reduce bargaining power by eroding commitment. Poulsen and Tan (2007) show that information about the acceptance threshold of one party backfires. Poulsen and Roos (2010) further document that subjects learn to avoid harmful information. In these experiments more information hurts as it weakens the bargaining position. In our setup more information - more monitoring - puts the manager in too strong a position. The latter only hurts the manager if the worker anticipates that he will be overruled, and therefore does not gather information. Although the strategic situation is thus different, our results corroborate the existing evidence: willful ignorance can be a useful tool in strategic interactions. ${ }^{2}$

Second, our paper connects to two recent experimental studies that investigate the allocation of decision rights in organizations. Like the present paper, Fehr, Herz, and Wilkening (2010) focus on the motivational consequences of delegation. Their setup very closely follows Aghion and Tirole (1997) such that both managers and workers can exert effort to find information on the available projects. They find that managers retain too much formal control. Furthermore, managers or workers with formal authority exert more search effort, while those with no formal authority exert less effort than predicted by Aghion and Tirole (1997). In Lai and Lim (2012) managers decide whether to delegate decision rights to workers or not. In case authority is kept, managers and workers communicate, where communication is organized as a cheap talk game. Workers have full information on the payoff consequences of the decision at hand, thus the delegation decision has no incentive effect on information gathering as in Aghion and Tirole (1997). Lai and Lim (2012) find that managers keep too much control. Arguably the reason is that workers do not behave fully strategically in the cheap talk game, such that communication reveals a lot of information.

\footnotetext{
${ }^{2}$ Individuals with social preferences might also choose strategic ignorance in order not to learn potentially negative consequences of their actions for others. See for example Dana, Weber, and Kuang (2007) and Grossman (2010). We focus on strategic ignorance that might arise because individuals fear that their gathering of information affects the strategic behavior of other individuals.
} 
The main difference to both the above papers is that in our experiment managers cannot formally delegate decision rights. ${ }^{3}$ Only our paper thus investigates whether managers learn to employ strategic ignorance to effectively abstain from making the decision themselves. This connects well to a strand in the management literature - see for example Foss (2003) and Foss, Foss, and Vázquez (2006) - which indeed suggests that commitment issues concerning unwanted managerial meddling are an important organizational concern.

\section{Model}

Our model of delegation adapts Aghion and Tirole (1997) for implementation in a laboratory experiment. In their model managers and workers simultaneously decide how much to invest in a costly and stochastic information gathering technology. This technology can provide both managers and workers with information on the projects. Workers hold real authority, if they happen to receive informative signals, while managers happen not to receive informative signals.

We make the following adaptations to get a clean experimental test of the main mechanism in Aghion and Tirole (1997). First, managers cannot gather information on the projects independently from workers. Instead, they decide whether or not to monitor. Monitoring allows managers to access any information gathered by their workers. This clarifies the strategic interaction between managers and workers. Second, managers and workers make binary monitoring and information gathering choices. This simplifies comparisons when analyzing the impact of monitoring by managers on information gathering by workers. Thirdly, managers and workers act sequentially. Managers initially decide whether or not to monitor their workers. Observing their managers' choices, workers decide whether or not to gather information on the investment projects. We can therefore directly see whether monitoring discourages information gathering by workers. Fourthly, the information that managers and workers receive is deterministically determined by their behavior. Since no chance moves are involved, we reduce the possibility that subjects are unduly influenced by risk aversion, or make mistakes when dealing with probabilities. In the following we describe our theoretical setup in more detail.

\footnotetext{
${ }^{3}$ There are further differences. Fehr, Herz, and Wilkening (2010) for example demonstrate that in their experiment control and effort choices seem to be driven by regret aversion. We argue in the discussion of our results that regret aversion is not consistent with our data.
} 


\subsection{Baseline Model of Delegation}

Consider a firm that consists of a manager and a worker. In this firm some investment project $k \in \mathcal{K}$ is implemented, where the set of possible projects is $\mathcal{K}=\{1,2, . ., K\}$. Projects differ in the payoffs they yield to manager and worker. The sets of possible payoffs are $\mathcal{M}=\left\{m_{1}, m_{2}, . ., m_{K}\right\}$ for the manager and $\mathcal{W}=\left\{w_{1}, w_{2}, . ., w_{K}\right\}$ for the worker. There is a one-to-one correspondence between these sets of payoffs generating exactly $K$ distinct payoff combinations. There is also a one-to-one correspondence between these payoff combinations and the investment projects, so that each payoff combination is connected with exactly one investment project. Manager and worker know the possible payoff combinations, but they initially do not know which payoff combination is connected to which investment project. There are $K$ ! different ways of assigning the $K$ payoff combinations to the $K$ investment projects, and initially each of these $K$ ! possible assignments is equally likely. Formally, the assignment of payoff combinations to the investment projects depends on an initially unknown state of the world $\theta \in \Theta$, with $\Theta=\{1,2, \ldots, K !\}$, where the prior probability for any state of the world equals $1 / K$ !. Given state $\theta$ project $k$ yields payoff $f_{m}(k, \theta)$ to the manager and payoff $f_{w}(k, \theta)$ to the worker.

\subsection{Sequence of Actions and Information}

Within firms the information generation process is decentralized, while the manager always keeps formal authority. The interaction between manager and worker is as follows. The manager first chooses whether to monitor the worker or not. Monitoring costs the manager $\phi>0$. After observing the monitoring decision, the worker decides whether to collect information or not. Collecting information costs the worker $\psi>0$. If the worker collects information, he learns the state of the world $\theta \in \Theta$. Otherwise, he learns nothing. The worker then recommends one of the projects $r \in \mathcal{K}$ to the manager. The manager observes whether the worker has gathered information and his recommendation. She then implements a project.

The information the manager holds after receiving the worker's recommendation depends on her monitoring choice and the worker's information gathering choice. If the worker gathers no information, the manager never has any information on any project. This holds no matter whether the manager monitors the worker or not. If the worker gathers information, the information of the manager depends on her monitoring choice. If she monitors the worker, she has the same information as the worker. She then knows the state of the world $\theta$ and thus the payoffs of all investment projects. If the manager does not monitor the worker, then 
the manager observes only the actual payoffs of the proposed project. She does not learn the exact state of the world. There thus remains some uncertainty concerning the payoffs of the projects that are not recommended by the worker.

\subsection{Interest Alignment}

In our experiment we are interested in how behavior changes as we change the interest alignment of the manager and the worker. Intuitively speaking, interests are aligned if both manager and worker want the same project to be implemented. We formalize this notion as follows. Let $m_{m}$ be the payoff for the manager if her most preferred project is implemented. Define $w_{w}$ analogously. Given that the manager gets her most preferred project we are interested in the resulting payoff for the worker. Thus, let $w_{m}$ be the payoff for the worker if the implemented project is most preferred by the manager. Equally, let $m_{w}$ be the payoff for the manager if the implemented project is most preferred by the worker. We then define

$$
\left(m_{m}-m_{w}, w_{w}-w_{m}\right)
$$

as our inverse measure for the interest alignment between manager and worker. It is twodimensional since collapsing our measure into one dimension would imply that in strategically different situations the interest alignment between worker and manager can be the same. We show that only the inverse interest alignment of managers with workers $w_{w}-w_{m}$ determines whether monitoring destroys workers' incentives to gather information. Monitoring thus discourages information gathering only if workers consider managers to be their foes rather than their friends. Further, the inverse interest alignment of workers with managers $m_{m}-m_{w}$ determines the costs of losing control to managers. The relative strength of these effects determine managers' incentives to monitor. ${ }^{4}$

\section{Strategic Ignorance and Real Authority}

In this section we investigate equilibrium behavior under the assumption that managers and workers are fully rational and maximize their own monetary payoffs. In the above dynamic game the manager has incomplete information on the projects' payoffs if she does not monitor and the worker gathers information. Given the recommended project the manager has to

\footnotetext{
${ }^{4}$ Given the product order, the set of possible interest alignments is only a partially ordered set. Interest alignment thus deteriorates if and only if both $m_{m}-m_{w}$ and $w_{w}-w_{m}$ weakly increase while at least one difference strictly increases. There is a monotonic relationship between equilibrium monitoring and interest alignment if and only if any decrease in interest alignment has a monotonic impact on monitoring.
} 
form beliefs about the state of the world. The relevant equilibrium concept is perfect Bayesian equilibrium. A strategy for the manager is a monitoring choice plus a project implementation rule conditional on her own monitoring choice, on the worker's information gathering choice, on the worker's project recommendation, and on the potentially revealed payoffs of the recommended project. A strategy for the worker is an information gathering rule conditional on the manager's monitoring choice, and a subsequent project recommendation rule conditional on the manager's monitoring choice, on the worker's own information gathering choice, and in case of information gathering, on the state of the world.

In equilibrium these strategies maximize expected payoffs given beliefs about the state of the world and the other individual's equilibrium strategy. Beliefs must be consistent with equilibrium strategies whenever possible. This implies that the manager must update her beliefs after receiving a recommendation by an informed worker. Updated beliefs depend on the recommendation, on the worker's equilibrium recommendation rule, and on the revealed payoffs of the recommended project. In the following we intuitively describe the equilibrium behavior of manager and worker; later we will derive more exact predictions for the parameters used in the experiment.

\subsection{Implementation Decisions and Delegation of Real Authority}

We start our analysis with the equilibrium project implementation choices of the manager. Suppose first that the worker does not gather information. Since the manager has no information, any implementation decision is equally optimal and yields expected payoffs of

$$
\frac{1}{K} \sum_{k \in \mathcal{K}} m_{k}=\bar{m} \quad \text { and } \quad \frac{1}{K} \sum_{k \in \mathcal{K}} w_{k}=\bar{w}
$$

for the manager and the worker, respectively. Suppose second that the worker gathers information while the manager monitors the worker. The manager then has full information on all projects and implements a project that yields her the highest payoff $m_{m}$ and the worker the payoff $w_{m}$.

Suppose thirdly that the worker gathers information while the manager does not monitor the worker. The manager then sees the payoffs $f_{m}(r, \theta)$ and $f_{w}(r, \theta)$ belonging to the recommended project $r$. Although this reveals some information on the state of the world $\theta$, the manager cannot directly observe $\theta$ since she cannot observe the payoffs belonging to the projects other than $r$. Let $p\left(\theta^{\prime} ; r, f_{m}(r, \theta), f_{w}(r, \theta)\right)$ be her posterior beliefs that the state of 
the world equals $\theta^{\prime}$ after the informed worker has recommended project $r$ while the state of the world equals $\theta$. Note that in equilibrium this belief also reflects the worker's equilibrium recommendation rule.

The manager has to decide whether she wants to follow the worker's recommendation or pick another project. It is optimal to follow the recommendation $r$ if and only if

$$
f_{m}(r, \theta) \geq \max _{k \in K}\left\{\sum_{\theta^{\prime} \in \Theta} p\left(\theta^{\prime} ; r, f_{m}(r, \theta), f_{w}(r, \theta)\right) f_{m}\left(k, \theta^{\prime}\right)\right\} .
$$

Otherwise, she implements a project $k$ that yields the maximum expected payoff given her posterior beliefs $p$. In any case the implemented project yields her the highest expected payoff given her updated belief.

Monitoring affects the distribution of formal and real authority as follows. The manager always has formal authority - she makes the project implementation decision. If the worker gathers information and the manager monitors, she keeps real authority. The reason is that she implements her most preferred project, and there is nothing the worker can do about this, as his recommendation has no impact on the implementation choice. If the manager does not monitor, she transfers some real authority to the worker. The reason is that the worker can influence the beliefs of the manager by recommending a project. The worker now has some real authority since he can affect the final implementation choice.

In Aghion and Tirole (1997) there exists a very bad project that yields manager and worker very low payoffs in case of implementation. An uninformed manager thus follows an informed worker's recommendation if the worker proposes his most preferred project. The reason is that an uninformed manager who overrules his worker might implement the very bad project by chance. We assume that this also holds in our setup such that

$$
m_{k}>\frac{1}{K-1} \sum_{l \in \mathcal{K} \backslash\{k\}} m_{l} \text { for } m_{k}=m_{w} .
$$

The assumption imposes a minimum level of interest alignment between manager and worker. If the worker gathers information while the manager does not monitor, the worker thus receives all real authority since he can effectively implement his most preferred project. This yields the manager payoff $m_{w}$ and the worker payoff $w_{w}$. 


\subsection{Information Gathering and Delegation as Worker Empowerment}

Building on the implementation choices of the manager, we can turn to the recommendation behavior and information gathering of the worker. If the worker gathers no information, his recommendation has no informational content and he and the manager receive expected payoffs $\bar{w}$ and $\bar{m}$. If the worker gathers information and the manager monitors him, the manager implements her preferred project and the worker receives payoff $w_{m}$. Finally, if the worker gathers information and the manager does not monitor him, he can implement his most preferred project since by assumption the manager follows his recommendation. The worker then receives payoff $w_{w}$.

The worker gathers information if and only if his increase in expected payoffs exceeds the information gathering costs $\psi$. We thus must have

$$
\bar{w} \leq \begin{cases}w_{m}-\psi & \text { if the manager monitors } \\ w_{w}-\psi & \text { if the manager does not monitor. }\end{cases}
$$

It is crucial to note that the incentives to gather information depend on whether the manager monitors the worker or not. Monitoring reduces the incentives to gather information by

$$
w_{w}-w_{m}
$$

In our two-dimensional measure of interest alignment, this expression is the inverse interest alignment of managers with workers. Monitoring can thus result in a loss of initiative as discussed by Aghion and Tirole (1997) and Baker, Gibbons, and Murphy (1999).

\subsection{Monitoring and Loss of Control}

We finally turn to the monitoring choice of the manager. Whether it is optimal to monitor depends crucially on whether monitoring discourages information gathering by the worker. There are three cases. First, suppose the worker does not gather information no matter whether the manager monitors or not. In this case the manager always takes an uninformed decision. To save costs the manager optimally refrains from monitoring the worker. Second, suppose the worker gathers information no matter whether he is monitored or not. If the manager monitors, she then gets her most preferred project and thus payoff $m_{m}$. If she does not monitor, the worker manages to push through his most preferred project and the manager 
gets payoff $m_{w}$. The manager then optimally monitors the worker if and only if

$$
m_{m}-m_{w} \geq \phi .
$$

In this situation the manager loses payoff $m_{m}-m_{w}$ by delegating real authority to the worker. In our two-dimensional measure of interest alignment, this expression is the inverse interest alignment of managers with workers. It is the consequence of her loss of control as discussed by Aghion and Tirole (1997) and Baker, Gibbons, and Murphy (1999).

Finally, suppose the worker gathers information if and only if he is not monitored. If the manager monitors, the worker gathers no information. The manager then makes an uninformed choice and gets expected payoff $\bar{m}$. In addition she incurs the monitoring costs $\phi$. If the manager does not monitor, the worker gathers information and recommends his most preferred project. The manager then gets payoff $m_{w}$ which exceeds the expected payoff resulting from an uninformed implementation decision by assumption (4).

\subsection{Comparative Statics}

In her decision whether or not to monitor the worker, the manager thus has to take into account two effects. First, monitoring reduces the worker's incentives to gather information. Second, monitoring allows the manager to push through her most preferred project in case the worker gathers information. These effects correspond to the two dimensions of our measure of interest alignment. Keeping the respective other dimension fixed, monitoring incentives are weakly decreasing in the inverse interest alignment $w_{w}-w_{m}$ of managers with workers, and increasing in the inverse interest alignment $m_{m}-m_{w}$ of workers with managers. Comparative static predictions result from these two countervailing effects, thus equilibrium monitoring decisions can depend on the interest alignment in a non-monotonic way. We test exactly such non-monotone comparative static predictions in our experiment.

\section{Delegation and Loss Aversion}

The empirical evidence cited in the introduction suggests that managers might keep control even if this has disadvantageous consequences for organizational efficiency. We believe that managers might exhibit such control preferences since they fear disappointment if delegation turns out not to be advantageous - although such fear is largely irrational. In the following we explore this idea using the model of reference-dependent preferences by Köszegi and Rabin (2006). Our aim is to refine comparative static predictions. 


\subsection{Irrational Workers and Biased Managers}

Our formalization requires two components. For once it must contain heterogeneity in worker behavior. We assume that with some small probability $\pi \in] 0,1[$ workers behave irrationally. For simplicity these workers always gather information with probability $1 / 2$ no matter whether they are monitored or not. They also always recommend each project with equal probability $1 / K$. With probability $1-\pi$ workers behave rationally. These workers maximize expected payoffs.

The second component of our formal analysis are managers' reference-dependent preferences in the spirit of Köszegi and Rabin (2006). Let $q\left(m_{k}\right)$ be the probability with which the manager expects to receive payoff $m_{k} \in \mathcal{M}$. The manager also compares her payoffs with the possible payoffs of some reference lottery. Let $\tilde{q}\left(m_{l}\right)$ be the probability with which she expects to get payoff $m_{l} \in \mathcal{M}$ according to some reference lottery. The expected utility of the manager can then be expressed as

$$
\sum_{k \in \mathcal{K}} m_{k} q\left(m_{k}\right)-\gamma \sum_{k \in \mathcal{K}} \sum_{l \in \mathcal{K}} \max \left\{m_{l}-m_{k}, 0\right\} \tilde{q}\left(m_{l}\right) q\left(m_{k}\right) .
$$

The first term are the expected realized payoffs. The second term is the reference-dependent utility component. The manager compares every payoff $m_{k}$ with every reference payoff $m_{l}$. She experiences a utility loss if the realized payoff $m_{k}$ is less than the reference payoff $m_{l}$. There is no utility gain if the realized payoff exceeds the reference payoff. The manager is thus loss averse. The disutility of the disadvantageous payoff comparisons $m_{l}-m_{k}$ is weighted with the probability $\tilde{q}\left(m_{l}\right)$ from the reference lottery. The manager forms expectations with respect to the realized payoffs $m_{k}$. The positive parameter $\gamma$ defines the relative importance of the reference-dependent utility component.

\subsection{Endogenous Reference Point and Equilibrium Concept}

The crucial assumption in any application of loss aversion is the reference point. Köszegi and Rabin (2006) argue that reference lotteries are endogenously shaped by rational expectations. In a slight deviation from their definition we assume that the reference lottery is exclusively determined by the rational behavior of workers. The reference probability that a certain payoff realizes thus is the equilibrium probability with which this payoff realizes if managers are matched to rational workers. This simplifies the exposition and reflects the idea that irrational behavior is improbable and exceptional. 
Köszegi and Rabin (2006) further argue that reference lotteries are sticky in the sense that they need not adjust immediately as the strategic interaction unfolds. It is thus important to specify when reference lotteries are formed and how they adjust to new information. We assume that reference lotteries are formed directly after the monitoring decisions, and are thus conditional on the monitoring choices. We believe this to be reasonable since managers focus on future outcomes when pondering their monitoring choices. We further assume that for the remaining strategic interaction reference lotteries are stuck in the minds of managers.

Since there is incomplete information our equilibrium definition complies with perfect Bayesian equilibrium. Managers in addition take into account that with some small probability $\pi$ workers are irrational. The equilibrium concept is augmented to account for loss aversion and endogenous reference points as suggested by Köszegi and Rabin (2006, pp.1143-1146). Managers consequently form their reference lotteries based on probable equilibrium behavior. They correctly anticipate their own future behavior. Monitoring and implementation choices maximize concurrent expected utility.

\subsection{Monitoring Incentives and Loss Aversion}

We next investigate the impact of loss aversion on monitoring incentives. The technical analysis in Appendix A shows that there are two main cases depending on whether or not monitoring discourages the information gathering of rational workers. This case distinction turns out to be purely driven by the interest alignment and thus by payoff fundamentals. In the following we look at these two cases separately.

We first describe the monitoring incentives for loss averse managers if monitoring does not discourage information gathering by workers who behave rationally. Monitoring incentives are then given by

$$
\begin{aligned}
(1-\pi)\left(m_{m}-m_{w}\right)+\frac{\pi}{2} & \left(m_{m}-\frac{1}{K} \sum_{k \in \mathcal{K}} \max \left\{A\left(m_{k}, \gamma\right), R\left(m_{k}, \gamma\right)\right\}\right) \\
& +\frac{\pi}{2 K} \sum_{k \in \mathcal{K}} \gamma\left(\max \left\{m_{w}-m_{k}, 0\right\}-\max \left\{m_{m}-m_{k}, 0\right\}\right)-\phi
\end{aligned}
$$

In this expression $A\left(m_{k}, \gamma\right)$ is the expected utility of a loss averse manager who does not monitor and then follows the recommendation of a worker to implement a project that yields the manager a payoff of $m_{k} . R\left(m_{k}, \gamma\right)$ is the corresponding expected utility if the manager rejects the recommendation and instead implements an unknown alternative project. 
The first term in (9) is the utility increase by pushing through her preferred project rather than the project preferred by the worker in case the worker behaves rationally. The second term shows the positive consequences of control if an irrational worker gathers information but then recommends an arbitrary project. The third term describes the expected utility in case the worker behaves irrationally by not gathering information. The manager must then make a random implementation decision no matter whether she monitors or not. But monitoring improves the reference lottery from getting $m_{w}$ to getting $m_{m}$. This increases expected suffering from loss aversion, and therefore discourages monitoring.

We next describe the monitoring incentives for loss averse managers if monitoring discourages information gathering by workers who behave rationally. Monitoring incentives are then

$$
\begin{aligned}
(1-\pi)\left(\frac { 1 } { K } \sum _ { k \in \mathcal { K } } \left(m_{k}\right.\right. & \left.\left.-\gamma \frac{1}{K} \sum_{j \in \mathcal{K}} \max \left\{m_{j}-m_{k}, 0\right\}\right)-m_{w}\right) \\
& +\frac{\pi}{2}\left(m_{m}-\frac{1}{K} \sum_{k \in \mathcal{K}} \max \left\{A\left(m_{k}, \gamma\right), R\left(m_{k}, \gamma\right)\right\}\right) \\
+ & \frac{\pi}{2 K} \sum_{k \in \mathcal{K}} \gamma\left(\max \left\{m_{w}-m_{k}, 0\right\}-\frac{1}{K} \sum_{j \in \mathcal{K}} \max \left\{m_{j}-m_{k}, 0\right\}\right)-\phi
\end{aligned}
$$

The first term of this expression shows that monitoring strongly reduces the expected utility of loss averse managers in particular if workers behave rationally. The reason is that monitoring then discourages information gathering, which makes the reference lottery stochastic and exposes the manager to losses with positive probability. The remaining terms are essentially interpreted as in expression (9).

The above case distinction illustrates that whether loss aversion increases or decreases the incentives to monitor depends on the interest alignment. There are two cases. In the first case monitoring does not discourage information gathering - the interest alignment of managers with workers is strong. Loss aversion then typically encourages more monitoring. The reason is that monitoring provides managers with the option to improve payoffs in case workers gather information but then irrationally recommend the wrong project. That monitoring also has a negative impact on expected utility by influencing the reference point is likely to be secondary.

In the second case monitoring discourages information gathering - the interest alignment of managers with workers is weak. Monitoring then makes the reference lottery truly stochastic 
which creates expected losses even when facing rational workers. Again monitoring provides managers with the option to react in case workers gather information but then make an irrational recommendation. The impact on the reference point in case workers gather no information is ambiguous. Overall, loss aversion is likely to decrease monitoring incentives if monitoring discourages information gathering by rational workers. The reason is that monitoring creates disadvantageous change in the reference lottery, which has a strong effect via the large majority of workers who behave rationally.

\subsection{Comparative Statics with Loss Aversion}

Given our theoretical analysis we can now investigate how loss aversion affects comparative static predictions. We are particularly interested to find out whether loss aversion changes the link between interest alignment and monitoring incentives.

Suppose first that the inverse interest alignment of managers with workers increases while keeping the inverse interest alignment of workers with managers fixed. In that case we might move from a situation in which monitoring has no impact on information gathering to a situation in which monitoring discourages information gathering. In the former case loss aversion increases monitoring incentives, whereas in the latter case loss aversion decreases monitoring incentives. This implies that loss aversion overall amplifies the weakly negative impact of the inverse interest alignment $w_{w}-w_{m}$ on monitoring incentives.

Suppose second that the inverse interest alignment of workers with managers increases while keeping the inverse interest alignment of managers with workers fixed. This change in interest alignment now affects the impact of loss aversion on monitoring incentives via two channels. The first channel is that loss aversion increases the utility gain from keeping control in case irrational workers gather information but recommend wrong projects: the second terms in both (9) and (10) increase. The second channel is the reference point effect which in general decreases monitoring incentives: the third terms in both (9) and (10) decrease. The impact of loss aversion on comparative statics are thus ambiguous. However, it is possible that loss aversion reverses the positive impact of the inverse interest alignment $m_{m}-m_{w}$ on monitoring incentives. In that case loss aversion overturns comparative static predictions. 


\section{Hard versus Soft Information}

We have argued that loss averse managers might be unwilling to delegate decision rights even if delegation is in their own monetary interest. But it might be premature to conclude from excess monitoring in an experiment that behavioral biases matter, since excess monitoring could also reflect mistakes and noise in managers' decision processes. The above analysis of loss aversion provides useful insights, but the derived comparative static predictions can be ambiguous.

We thus vary in the experiment the information that managers have when they do not monitor their workers while workers gather information. The idea is to make monitoring more tempting for loss averse managers, while keeping monetary monitoring incentives largely unchanged. We later argue that other explanations for preferences for control make no systematic comparative static predictions. If observed monitoring varies systematically with the information structure, then this provides - tentative - evidence for loss aversion as driver of behavioral preferences for control.

\subsection{Soft Information and Monetary Monitoring Incentives}

To vary the strategic situation without strongly changing monetary equilibrium monitoring incentives, we change the information that is available to the manager if she does not monitor and the worker collects information. In the original setup - we call it hard information - the manager observes the actual payoffs of the proposed project. In the adapted setup - we call it soft information - the manager no longer observes the payoffs of the proposed project, but only which project is recommended.

To clarify the difference to hard information suppose that the manager does not monitor the worker while the worker gathers information. Suppose further that the worker recommends project $k \in \mathcal{K}$. Although the manager does not see the payoffs of the recommended project, the worker's recommendation choice might nevertheless reveal some information on the state of the world. For example the worker could always recommend his most preferred project. Let $\tilde{p}\left(\theta^{\prime} ; r\right)$ then be the manager's posterior beliefs that the state of the world equals $\theta^{\prime}$ after the informed worker has recommended project $r$. Given her beliefs $\tilde{p}$ it is optimal to follow 
the worker's recommendation $r$ if and only if

$$
\sum_{\theta^{\prime} \in \Theta} \tilde{p}\left(\theta^{\prime} ; r\right) f_{m}\left(r, \theta^{\prime}\right) \geq \max _{k \in K}\left\{\sum_{\theta^{\prime} \in \Theta} \tilde{p}\left(\theta^{\prime} ; r\right) f_{m}\left(k, \theta^{\prime}\right)\right\} .
$$

Under both hard and soft information the manager implements the project which maximizes her expected payoff given her updated beliefs.

It is unproblematic to adapt the definitions for strategies and perfect Bayesian equilibrium to account for the new information structure. The only difference is that with soft information the strategic situation between an uninformed manager and an informed worker turns into a cheap-talk game. Monetary monitoring incentives depend on the outcomes of the cheap-talk game. In this cheap-talk game the only available message is the recommendation. Given our assumptions on minimum interest alignment there exists an equilibrium in which the worker proposes his most preferred project and the manager follows the recommendation. Given this informative equilibrium, the behavioral outcome is essentially the same with hard or with soft information. There are then no behavioral differences at the recommendation and implementation stage between hard and soft information. In this case our treatment variation serves the intended purpose of changing the information structure while leaving the monetary equilibrium incentives to monitor unchanged. ${ }^{5}$

\subsection{Soft Information and Loss Aversion}

But the information structure at the implementation stage affects monitoring incentives if managers are loss averse. Consider an uninformed manager who does not monitor her worker and faces the recommendation of an informed worker. Under hard information the manager observes the project characteristics of the recommendation. She thus knows what she gets if she follows the workers recommendation, and can respond to irrational recommendations with her project choice. Under soft information the manager does not observe the payoffs of the recommended project. Even though the manager knows that most workers recommend

\footnotetext{
${ }^{5}$ There also exists a babbling equilibrium in which the worker makes a random recommendation, and the manager makes a random implementation decision. But it seems intuitive that in case of indifference workers in an experiment recommend their preferred project. Parameters in the experiment are also chosen such that the above informative equilibrium Pareto-dominates the babbling equilibrium. Forward induction further implies that gathering information only makes sense if workers expect their recommendations to affect implementation. We consequently consider it most likely that managers and workers act according to the informative equilibrium in which the worker recommends his most preferred project.
} 
the project that is best for them, uncertainty remains because some workers might make mistakes. With soft information the manager cannot adjust her project choice in case the worker makes an unexpected recommendation. Loss averse managers might thus opt for monitoring to avoid that they follow wrong recommendations. In the treatment with soft information we would thus expect more monitoring and thus less effective delegation by managers as compared to the treatment with hard information. This holds even though monetary monitoring incentives are largely unchanged.

In Appendix A we make this intuition precise. We demonstrate that going from hard to soft information increases the monitoring incentives for loss averse manager by

$$
\frac{\pi}{2 K} \sum_{k \in \mathcal{K}}\left(\max \left\{A\left(m_{k}, \gamma\right), R\left(m_{k}, \gamma\right)\right\}-A\left(m_{k}, \gamma\right)\right)
$$

This increases in monitoring incentives is unambiguously positive. Its magnitude depends on interest alignment only via the reference payoff $m_{w}$ that managers expect to get if they do not monitor workers.

\section{Experimental Design}

\subsection{Parameters and Equilibrium Predictions}

In our experiment we test the possibly non-monotonic impact of the interest alignment of manager and worker on equilibrium monitoring and information gathering decisions. We consider three treatments: full, strong, and weak interest alignment. In all treatments there are three investment projects; we set $\mathcal{M}=\mathcal{W}=\{15,80,100\}$ so that $m_{m}=w_{w}=100$ and $\bar{m}=\bar{w}=65$. Table 1 shows the possible payoff combinations of the investment projects for each treatment separately, and which projects are preferred by manager and worker. The inverse measures for the alignment of interest are thus $(0,0)$ in full alignment, $(20,20)$ in strong alignment, and $(20,85)$ in weak alignment. Our measure of interest alignment therefore generates a clear ordering. In the treatments with strong and weak interest alignment, the manager actually gets the same payoff if the workers implements his most preferred project. The monetary costs for monitoring $\phi$ and information gathering $\psi$ are 10 in all treatments.

We first discuss workers' equilibrium incentives to gather information. Workers are not loss averse while managers who do not monitor follow the recommendation of informed workers who recommend their most preferred project. Incentives to gather information thus depend on 
Table 1: Payoff Combinations in Treatments

\begin{tabular}{lccc}
\hline \hline Treatment & Manager Preferred & Worker Preferred & Others \\
\hline Full Alignment & \multicolumn{2}{c}{$(100,100)$} & $(80,80)$ \\
Strong Alignment & $(100,80)$ & $(80,100)$ & $(15,15)$ \\
Weak Alignment & $(100,15)$ & $(80,100)$ & $(15,80)$ \\
\hline \hline
\end{tabular}

Note: the table shows the possible payoff combinations. The first entry corresponds to the payoff for the manager, the second to the payoff for the worker.

the monitoring choices of managers but not on their loss aversion. With full interest alignment both manager and worker have the same most preferred project. Even an informed manager thus implements the worker's most preferred project. Since the worker is never overruled, his incentives to gather information are not affected by whether the manager monitors him or not. The worker gathers information since $w_{w}-\psi=100-10>65=\bar{w}$. With strong interest alignment an informed manager implements her most preferred project. However, the costs of gathering information are sufficiently low so that the worker nevertheless has incentives to gather information even if he is monitored. This holds because $w_{m}-\psi=80-10>65=\bar{w}$. Under weak alignment a monitoring manager again implements her most preferred project, but this time this really hurts the worker. Consequently, the worker only gathers information if the manager abstains from monitoring since $w_{m}-\psi=15-10<65=\bar{w}$.

Table 2 summarizes the incentives of managers to monitor given the equilibrium behavior of workers who behave rationally. Suppose that managers are not loss averse so that their loss aversion parameter $\gamma$ equals zero. Under full interest alignment the worker implements the manager's most preferred project anyway, thus the manager does not monitor in equilibrium to save costs. Under strong interest alignment monitoring does not discourage information gathering while the manager can implement her most preferred project. It is optimal for the manager to monitor since $m_{m}-m_{w}=100-80>10=\phi$. Under weak interest alignment monitoring discourages information gathering. Because the manager otherwise has to make an uninformed implementation decision, it is optimal for her not to monitor the worker. Under weak alignment we should thus observe that the manager uses strategic ignorance to effectively delegate real authority to the worker. Adding a small fraction of workers who do not behave rationally does not affect equilibrium predictions. 
Table 2: Monitoring Incentives

\begin{tabular}{lccccc}
\hline \hline & \multicolumn{5}{c}{ Loss Aversion Parameter $\gamma$} \\
\hline & 0.00 & 5.00 & 10.00 & 15.00 & 20.00 \\
\hline $0 \%$ Irrational & & & & & \\
\hline Full Alignment & -10.00 & -10.00 & -10.00 & -10.00 & -10.00 \\
Strong Alignment & 10.00 & 10.00 & 10.00 & 10.00 & 10.00 \\
Weak Alignment & -25.00 & -119.44 & -213.89 & -308.33 & -402.78 \\
\hline Change Soft Info (Full) & 0.00 & 0.00 & 0.00 & 0.00 & 0.00 \\
Change Soft Info (Strong \& Weak) & 0.00 & 0.00 & 0.00 & 0.00 & 0.00 \\
\hline \hline 5\% Irrational & & & & & \\
\hline Full Alignment & -9.75 & -8.50 & -7.25 & -6.00 & -4.75 \\
Strong Alignment & 9.25 & 7.58 & 5.92 & 4.25 & 2.58 \\
Weak Alignment & -24.00 & -113.38 & -202.75 & -292.13 & -381.50 \\
\hline Change Soft Info (Full) & 0.63 & 3.75 & 6.88 & 10.00 & 13.13 \\
Change Soft Info (Strong \& Weak) & 0.63 & 3.33 & 6.04 & 8.75 & 11.46 \\
\hline \hline 10\% Irrational & & & & & -2.00 \\
\hline Full Alignment & 1.25 & 7.50 & 13.75 & 20.00 & 26.25 \\
Strong Alignment & -9.50 & -7.00 & -4.50 & -2.00 & 0.50 \\
Weak Alignment & 8.50 & 5.17 & 1.83 & -1.50 & -4.83 \\
\hline Change Soft Info (Full) & -23.00 & -107.31 & -191.61 & -275.92 & -360.22 \\
Change Soft Info (Strong \& Weak) & 1.25 & 12.08 & 17.50 & 22.92 \\
\hline \hline
\end{tabular}

Note: numbers conditional on the loss aversion parameter $\gamma$ of managers and the fraction of irrational workers. Change Soft Info describes the increase in monitoring incentives when information is soft rather than hard.

We can next investigate how loss aversion affects monitoring incentives. Consider first the impact of changing from hard to soft information. In the table this is captured in the rows Change Soft Info. We distinguish between full interest alignment where $m_{w}=100$, and strong and weak interest alignment where $m_{w}=80$. The change in incentives depends on 
the fraction of workers who do not behave rationally. If there are no such workers, the change in incentives is zero. The reason is that the relevant case that promotes monitoring - workers gather information but make irrational recommendations - never occurs. If there exist some irrational workers, changing from hard to soft information increases monitoring incentives for loss averse workers. The table therefore demonstrates that we need both components of our model - loss averse managers and some irrational workers - to generate strong comparative static predictions with respect to the information structure.

The table also shows how the impact of loss aversion on monitoring incentives interacts with interest alignment. Even if all workers behave rationally, loss aversion turns out to decrease monitoring incentives in case interest alignment is weak. The reason is that monitoring then discourages information gathering, which results in a more disadvantageous reference lottery. Monitoring therefore increases the suffering from loss aversion if all workers behave rationally. This discourages monitoring if the fraction of workers who behave rationally is sufficiently large. Any positive consequences of changing information from hard to soft is dominated by the negative reference lottery effect. The model thus generates the clear prediction that under weak interest alignment we should observe only very little monitoring.

Under strong interest alignment predictions are more nuanced. If all workers are rational, loss aversion has no impact on monitoring incentives, as there are no irrational but informed recommendations. If some workers behave irrationally, loss aversion affects incentives. Under strong interest alignment parameters in our experiment are such that the negative reference lottery effect of monitoring dominates the benefits of keeping control. Loss aversion thus decreases monitoring incentives. If the level of loss aversion becomes sufficiently high, managers might eventually refrain from monitoring under hard information. Under soft information monitoring incentives remain positive for all levels of loss aversion. Overall the model thus makes no strong predictions under strong interest alignment.

Under full interest alignment we again get more clear-cut results. Since monitoring does not change reference lotteries, loss aversion unambiguously increases monitoring incentives. The model thus predicts an increase in monitoring. This positive effect should be stronger under soft than under hard information. 


\subsection{Procedures}

For each treatment we ran three sessions. Each session contained 18 or 20 participants. 170 subjects participated in the experiment. Subject were from the undergraduate student population of the University of Amsterdam, most of them studying economics (58\%). The experiment was programmed using the z-tree programming package by Fischbacher (2007). Each session consisted of four parts. Subjects were informed about this at the beginning of the experiment, but the subjects did not learn anything about the content of the different parts until the part actually started. After completing the instructions of part 1 and answering some control questions, each subject learned his role (either Manager or Worker). Throughout the experiment subjects kept the same role. The experiment was framed in an organizational setting. Hence, in the experiment we used the same phrasing as here. In total the first two parts of each session contained 30 periods. The experiment used a stranger design: each period the manager and the worker were anonymously and randomly matched. In each session we had two matching groups of 8 or 10 subjects. This yielded six independent observations per treatment.

The first part contained 20 periods in which subjects played the baseline model with hard information as explained in Section 2. At the end of each period, a summary of the manager's and worker's decisions and the resulting payoff in that period was shown to the subjects. Subjects did not receive information on the behavior of other managers and workers. The second part contained 10 periods in which subjects played the model with soft information. Interest alignment was kept constant.

In part 3 of the experiment we tried to measure subjects' pure preferences for control directly. We let subjects bid for the right to make the project choice, in a situation where the project choice is always made in the dark. This part is discussed in more detail in our discussion section that follows after presenting the results. The final part of the experiment was a questionnaire asking subjects among other things about their background characteristics. In part one and two the payoff to each subject in each period equalled the number of points of the implemented project minus possible costs the subjects incurred by becoming informed. The overall payoff for each subject equals the sum of points earned over all periods. The conversion rate was 150 points for 1 euro. Apart from that the subjects received 5 euro for filling in a questionnaire. Subjects earned on average 23 euros for 90-100 minutes. Sample instructions are included in Appendix B. 


\section{Results}

In this section we describe our empirical results. We first investigate how interest alignment affects aggregate monitoring and information gathering behavior. Summary statistics can be found in Tables 3 and 4 . We immediately observe that managers keep more real authority under strong interest alignment, whereas they delegate more real authority to workers by remaining ignorant under full and weak interest alignment. Further, monitoring discourages information gathering especially under weak interest alignment. Monitoring choices thus seem to be an optimal response to workers' information gathering. In consequence, managers delegate real authority under weak interest alignment, and workers gather information in all treatments.

In the remaining section we look at the above findings in greater detail. We first study managers' monitoring behavior and then investigate workers' information gathering decisions conditional on whether managers have kept real authority or not. We finally look at the project recommendation and implementation stage.

Table 3: Outcomes (Hard Information)

\begin{tabular}{lcccccccc}
\hline \hline & \multicolumn{3}{c}{ Monitoring and Information Gathering } & \multicolumn{2}{c}{ Project Implemented } \\
\hline & \multicolumn{2}{c}{ No Monitoring } & \multicolumn{2}{c}{ Monitoring } & & & \\
Treatment & No Info & Info & No Info & Info & $M_{\succ}$ & $W_{\succ}$ & $d_{\prec}$ \\
\hline Full Alignment & 6.96 & $\mathbf{6 5 . 1 8}$ & 0.18 & 27.68 & $\mathbf{9 5 . 1 8}$ & 4.82 \\
Strong Alignment & 5.52 & 19.83 & 29.14 & $\mathbf{4 5 . 5 2}$ & $\mathbf{6 1 . 2 1}$ & 24.14 & 14.66 \\
Weak Alignment & 19.29 & $\mathbf{6 1 . 2 5}$ & 15.54 & 3.93 & 17.68 & $\mathbf{6 5 . 0 0}$ & 17.32 \\
\hline \hline
\end{tabular}

Note: percentage wise overview of outcomes. Predictions from theory ignoring any behavioral biases in bold. $M_{\succ}$ and $W_{\succ}$ refers to manager's and worker's best project, $d_{\prec}$ denotes a dominated project. 
Table 4: Outcomes (Soft Information)

\begin{tabular}{lcccccccc}
\hline \hline & \multicolumn{3}{c}{ Monitoring and Information Gathering } & \multicolumn{2}{c}{ Project Implemented } \\
\hline & \multicolumn{2}{c}{ No Monitoring } & \multicolumn{2}{c}{ Monitoring } & & & \\
Treatment & No Info & Info & No Info & Info & $M_{\succ}$ & $W_{\succ}$ & $d_{\prec}$ \\
\hline Full Alignment & 4.64 & $\mathbf{4 3 . 2 1}$ & 1.07 & 51.07 & $\mathbf{9 5 . 7 1}$ & 4.21 \\
Strong Alignment & 8.28 & 14.14 & 24.83 & $\mathbf{5 2 . 7 6}$ & $\mathbf{6 7 . 2 4}$ & 17.24 & 15.52 \\
Weak Alignment & 9.29 & $\mathbf{6 4 . 2 9}$ & 22.86 & 3.57 & 18.21 & $\mathbf{6 2 . 1 4}$ & 19.64 \\
\hline \hline
\end{tabular}

Note: percentage wise overview of outcomes. Predictions from theory ignoring any behavioral biases in bold. $M_{\succ}$ and $W_{\succ}$ refers to manager's and worker's best project, $d_{\prec}$ denotes a dominated project.

\subsection{Monitoring behavior}

Figure 1 plots monitoring behavior over time. Replicating the timing in the experimental sessions (where subjects received instructions in between the two parts) information is hard in the first 20 periods of every treatment whereas it is soft in the last 10 periods. We see that initial monitoring rates are very similar in all three treatments, but managers quickly learn to delegate real authority under full and weak interest alignment. Making information soft creates an upwards jump in monitoring under both full and weak interest alignment. Monitoring rates remain high under full interest alignment, whereas they quickly drop under weak interest alignment. Changing from hard to soft information has essentially no effect on the high monitoring rate under strong interest alignment.

These patters are also apparent in the monitoring rates from Table 5. To account for time trends and learning we separately report results taking into account both observations from all periods and observations only from the second half of the periods. All non-parametric tests are based on the comparison of matching group averages to correct for any interdependencies between subjects from the same matching group. Between-group comparisons are based on Wilcoxon rank-sum tests, whereas within-group comparisons are based on Wilcoxon matchedpairs signed-ranks tests. Reported $p$-values of 0.00 indicates that the $p$-values are less than 0.005 


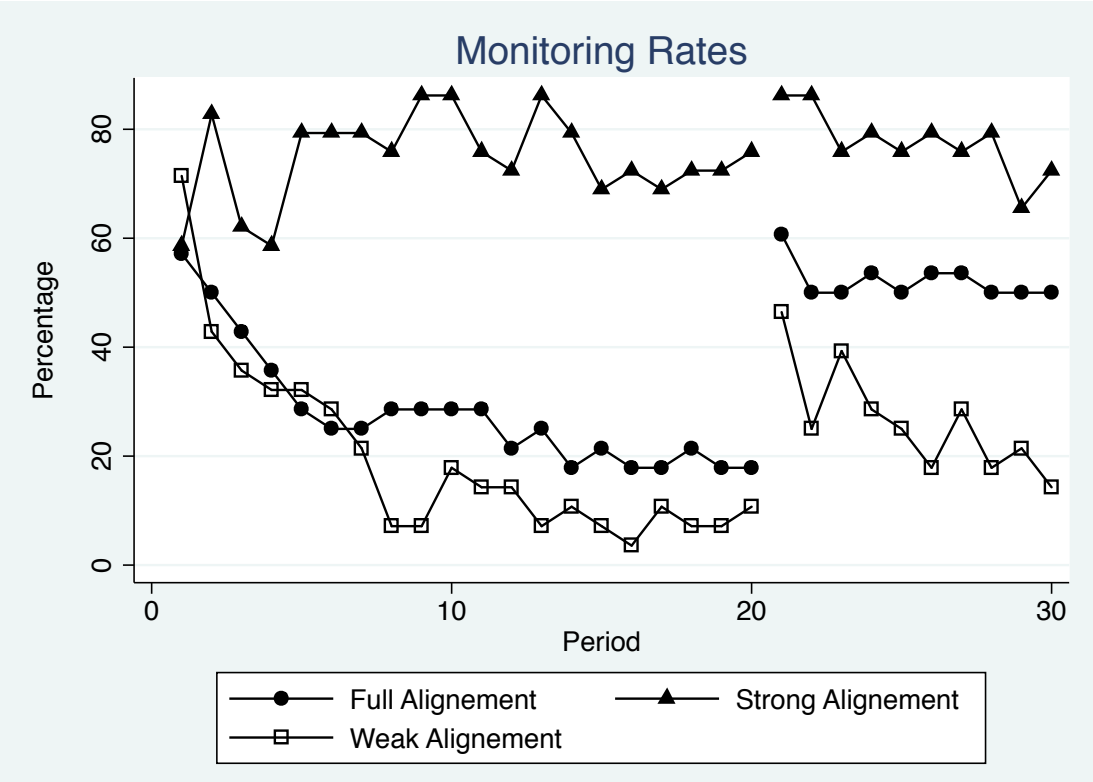

Figure 1: Monitoring

Table 5: Monitoring fractions

$p$-values

\begin{tabular}{lccc} 
Treatment & Hard Information & Soft Information & Hard vs. Soft \\
\hline Full Alignment & $0.29(0.23)$ & $0.54(0.53)$ & $0.04(0.04)$ \\
Strong Alignment & $0.75(0.74)$ & $0.77(0.74)$ & $0.75(0.75)$ \\
Weak Alignment & $0.19(0.09)$ & $0.26(0.20)$ & $0.12(0.14)$ \\
\hline$p$-values Full vs. Strong & $0.01(0.02)$ & $0.20(0.20)$ & \\
$p$-values Full vs. Weak & $0.52(0.52)$ & $0.11(0.05)$ & \\
$p$-values Strong vs. Weak & $0.00(0.00)$ & $0.00(0.00)$ & \\
\hline \hline
\end{tabular}

Note: p-values in last column from signed rank test. p-values in bottom rows based on ranksum tests. All statistical tests are based on distributions of matching group averages. Numbers without parentheses refer to data from all periods, numbers within parentheses to data only from the second half of the periods. 
We start by investigating comparative statics with respect to interest alignment with hard information. Consider first observations from all periods. Our statistical analysis confirms that managers monitor more when interest alignment is strong rather than when interest alignment is weak or full ( $p$-values of 0.00 and 0.01 ). There are no differences in monitoring behavior under full and weak interest alignment ( $p$-value of 0.52$)$. Results are the same when looking only at observations from later periods ( $p$-values of $0.00,0.02$, and 0.52 ).

We next investigate changes in monitoring rates as we move from hard to soft information. Consider first observations from all periods. Monitoring rates increase significantly only under full interest alignment ( $p$-values of 0.04). In the other treatments the increase in monitoring is not significant ( $p$-values of 0.75 and 0.12 ). Results remain the same if we take observations only from later periods ( $p$-values of $0.04,0.75$, and 0.14 ).

We finally study comparative statics with respect to interest alignment with soft information. Consider first observations from all periods. Monitoring rates remain significantly higher under strong than under weak interest alignment ( $p$-value of 0.00). But due to the high level of monitoring under full interest alignment, the difference between weak and full interest alignment is almost significant, while there are now no significant differences between full and strong interest alignment ( $p$-values of 0.11 and 0.20 ). This pattern becomes more pronounced if we only consider observations from later periods. Monitoring remains higher under strong than under weak interest alignment ( $p$-value of 0.00) while there is no significant difference between full and strong interest alignment ( $p$-value of 0.20). However, monitoring rates are now significantly higher under full than under weak interest alignment ( $p$-value of 0.05 ). We summarize our observations as follows.

Result 1 (Monitoring) (a) With hard information monitoring is more frequent under strong than under either weak or full interest alignment. (b) With soft information monitoring rates remain significantly higher under strong than under weak interest alignment. (c) Changing information from hard to soft increases monitoring under full interest alignment. (d) With soft information monitoring rates are thus the same under full and strong interest alignment, whereas monitoring becomes more frequent under full than under weak interest alignment over time. 


\subsection{Information Gathering}

We next turn to workers' information gathering decisions. For Figure 2 we pool observations from all periods and from hard and soft information. We present exact information gathering rates conditional on hard and soft information in Table 6 and Table 7.

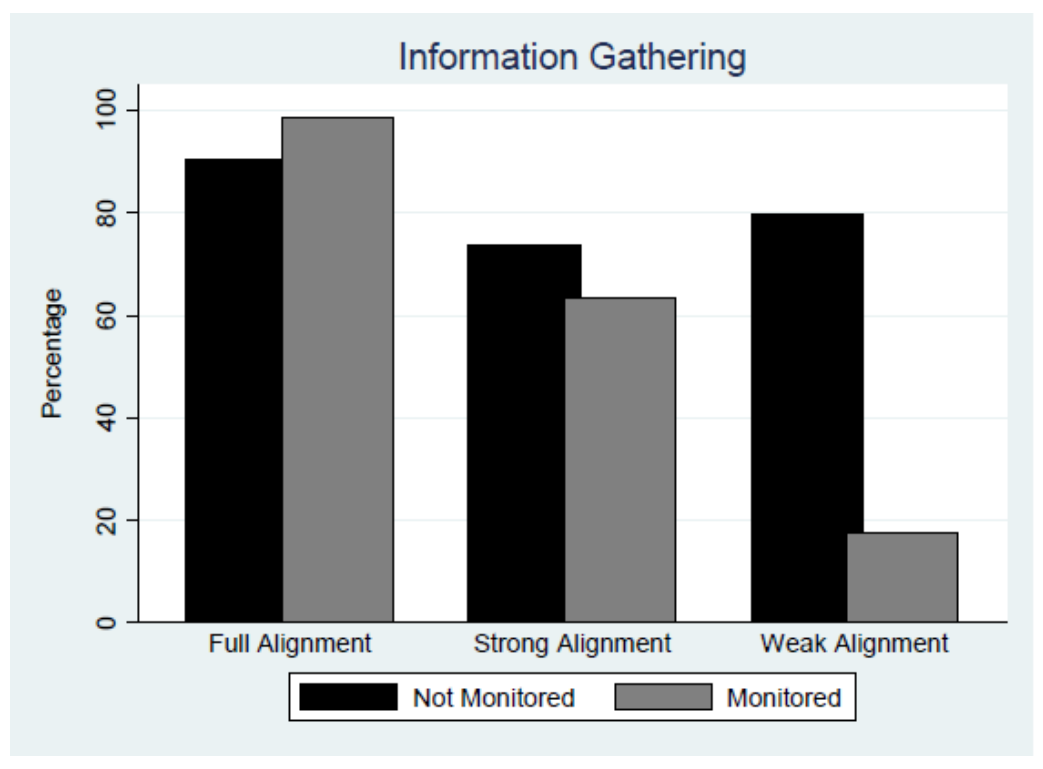

Figure 2: Information Gathering

The most obvious observation is that monitoring significantly decreases workers' information gathering under weak interest alignment ( $p$-value of 0.03 ). The difference is also economically significant. The loss of initiative resulting from monitoring makes it optimal for managers to remain ignorant. This holds irrespectively of whether information is hard or soft, and irrespectively of whether we consider observations from all periods or only from the second half ( $p$-values of 0.03 in all cases).

We further find that monitoring has no significant impact on information gathering rates under strong interest alignment with both hard and soft information ( $p$-values of 0.17 and 0.89 ). These findings also hold if we look at observations only from later periods ( $p$-values of 0.12 and 0.69 ). However, information gathering rates are rather low for workers who are not monitored. We will come back to this finding when investigating the recommendation and implementation behavior. 
Table 6: Information Gathering fractions Hard Information

\begin{tabular}{lccc}
\hline \hline Treatment & Not Monitored & Monitored & $\begin{array}{c}p \text {-values } \\
\text { Not Mon. vs. Mon }\end{array}$ \\
\hline Full Alignment & $0.89(0.94)$ & $0.99(1.00)$ & $0.04(0.09)$ \\
Strong Alignment & $0.77(0.83)$ & $0.60(0.57)$ & $0.17(0.12)$ \\
Weak Alignment & $0.77(0.79)$ & $0.17(0.02)$ & $0.03(0.03)$ \\
\hline$p$-values Full vs. Strong & $0.42(0.80)$ & $0.00(0.00)$ & \\
$p$-values Full vs. Weak & $0.04(0.02)$ & $0.00(0.00)$ & \\
$p$-values Strong vs. Weak & $0.26(0.11)$ & $0.00(0.00)$ & \\
\hline \hline
\end{tabular}

Note: p-values in last column from signed rank test. p-values in bottom rows based on ranksum tests. All statistical tests are based on distributions of matching group averages. Numbers without parentheses refer to data from all periods, numbers within parentheses to data only from the second half of the periods.

Under full interest alignment we see that monitoring actually increases workers' willingness to gather information when information is hard. This encouragement effect is significant no matter whether we look at observations from all periods or only from the second half ( $p$-values of 0.04 and 0.09 ). With soft information monitoring again increases information gathering but the effect is no longer significant. This result holds irrespectively of whether we look at data from all periods or only from the second half ( $p$-values of 0.17 and 0.43 ).

Another way to organize our data is to investigate the discouragement effect of monitoring. We define the discouragement effect of monitoring as the information gathering rate if not monitored minus the information gathering rate if monitored. Our data analysis shows that the discouragement effect is negative under full, zero under strong, and positive under weak interest alignment. We first consider the situation with hard information taking observations from all periods into account. Because monitoring discourages information gathering only under weak interest alignment, there are significant differences between weak and both full and strong interest alignment ( $p$-values of 0.00 ). We also find a significant difference in the discouragement effect between full and strong interest alignment ( $p$-value of 0.05). Relatively speaking monitoring therefore seems to have an encouraging effect on information gathering 
Table 7: Information Gathering fractions Soft Information

\begin{tabular}{lccc}
\hline \hline & & & $p$-values \\
Treatment & Not Monitored & Monitored & Not Mon. vs. Mon \\
\hline Full Alignment & $0.90(0.94)$ & $0.97(0.98)$ & $0.17(0.43)$ \\
Strong Alignment & $0.62(0.67)$ & $0.67(0.65)$ & $0.89(0.69)$ \\
Weak Alignment & $0.88(0.89)$ & $0.12(0.07)$ & $0.03(0.03)$ \\
\hline$p$-values Full vs. Strong & $0.02(0.03)$ & $0.00(0.00)$ & \\
$p$-values Full vs. Weak & $0.81(0.18)$ & $0.00(0.00)$ & \\
$p$-values Strong vs. Weak & $0.02(0.05)$ & $0.00(0.00)$ & \\
\hline \hline
\end{tabular}

Note: p-values in last column from signed rank test. p-values in bottom rows based on ranksum tests. All statistical tests are based on distributions of matching group averages. Numbers without parentheses refer to data from all periods, numbers within parentheses to data only from the second half of the periods.

under full interest alignment and hard information. Results continue to hold if we look only at observations from the second half of the experiment ( $p$-values of $0.01,0.00$, and 0.07). We next look at the discouragement effect of monitoring with soft information. Consider first observations from all periods. As with hard information the discouragement effect is stronger under weak than under both full and strong interest alignment ( $p$-values of 0.00 and 0.01). But now there no longer exists a significant difference between full and strong interest alignment ( $p$-value of 1.00). These results do not change if we only look at later observations ( $p$-values of $0.00,0.01$, and 0.46$)$.

We finally compare information gathering fractions depending on whether information is hard or soft. Sign rank tests reveal that only one difference out of twelve comparisons is statistically significant at the $5 \%$ level. Under strong interest alignment information gathering conditional on being monitored significantly increases when information becomes soft and we consider the second half of the periods only ( $p$-value of 0.05 ). In absolute size the increase is relatively small, from 0.57 to 0.65 . There is no significant effect when we take all periods into account. Whether information is hard or soft therefore has a negligible impact on workers' information gathering behavior. We summarize our results as follows. 
Result 2 (Information Gathering) (a) Under weak interest alignment, monitoring harms workers' information gathering. (b) Under strong interest alignment, monitoring has no impact on workers' information gathering. (c) Under full interest alignment, monitoring encourages workers' information gathering when information is hard. There is no such effect when information is soft. (d) Whether information is hard or soft has negligible effects on workers' information gathering behavior.

\subsection{Recommendation and Implementation}

We next turn to the recommendation and implementation stage. The overview depicted in Tables 3 and 4 suggests that managers typically can implement their most preferred project under strong interest alignment, whereas workers mostly manage to push through their most preferred project under weak interest alignment. But these tables only describe the outcomes of the recommendation and implementation stage. We next take a closer look at the actual proposals and project implementation choices made.

If workers do not acquire information, recommendation and implementation decisions are random since they are based on no information. We therefore focus on those observations in which workers acquire information. Under full interest alignment, workers essentially always recommend the project that is best for both, and managers essentially always follow these recommendations. ${ }^{6}$ Recommendation and implementation behavior is more dispersed when preferences diverge. Table 8 provides an overview of the choices then observed.

The data show that workers recommend their most preferred project only with a probability of $73 \%$ to $78 \%$ under strong interest alignment when they are monitored by their managers. But in that case the recommendation is irrelevant since managers have full information which they can use to overrule workers. In all other cases workers more or less always recommend their most preferred project. This holds under both strong and weak interest alignment, and with hard and soft information.

\footnotetext{
${ }^{6}$ For the 520 observations under hard information this is literally always the case. Under soft information we observe only 2 exceptions out of 263 observations.
} 
Table 8: Recommendation and Implementation

\begin{tabular}{lllll}
\hline \hline Treatment & Monitoring & Project & Recommended & Implemented \\
\hline Strong Alignment & No & $M_{\succ}$ & $0.07(0.02)$ & $0.26(0.17)$ \\
& & $W_{\succ}$ & $0.89(0.90)$ & $0.57(0.56)$ \\
& & $d_{\prec}$ & $0.04(0.07)$ & $0.17(0.27)$ \\
\hline \multirow{2}{*}{ Weak Alignment } & No & $M_{\succ}$ & $0.24(0.18)$ & $0.97(0.99)$ \\
& & $W_{\succ}$ & $0.73(0.78)$ & $0.03(0.01)$ \\
& & $d_{\prec}$ & $0.03(0.03)$ & $0.00(0.00)$ \\
& & $0.01(0.02)$ & $0.09(0.11)$ \\
& $M_{\succ}$ & $0.98(0.96)$ & $0.84(0.75)$ \\
& Yes & $d_{\prec}$ & $0.01(0.02)$ & $0.07(0.14)$ \\
\hline & & $M_{\succ}$ & $0.00(0.00)$ & $0.82(0.60)$ \\
& & $W_{\succ}$ & $0.95(1.00)$ & $0.18(0.40)$ \\
& $d_{\prec}$ & $0.05(0.00)$ & $0.00(0.00)$ \\
\hline \hline
\end{tabular}

Note: Fractions of recommended and implemented projects conditional on workers being informed. $M_{\succ}$ and $W_{\succ}$ refer to managers' and workers' preferred projects, while $d_{\prec}$ denotes dominated projects. Numbers without brackets refer to the part with hard information; the corresponding numbers for the part with soft information are in parentheses.

We next turn to the implementation behavior of managers. Consider first the case of strong interest alignment. The most striking observation is that managers who do not monitor do not always follow the recommendations of their informed workers: the workers' preferred project is implemented only in $57 \%$ of the cases with hard information, and in $56 \%$ of the cases with soft information. Managers who monitor essentially overrule workers to implement their most preferred project. Consider next the case of weak interest alignment. Managers who do not monitor then mostly follow the recommendations of their informed workers: the workers' most preferred project is implemented in $84 \%$ of the cases with hard information, and in $75 \%$ of the cases with soft information. Managers still mostly overrule workers to implement their most preferred project. However, they do so to a lesser degree: the project preferred by workers is now implemented in $18 \%$ of the cases under hard information, and in $40 \%$ of the cases with soft information. 
The data further show that recommendation and implementation patterns do not depend on whether information is hard or soft. Overall our analysis demonstrates that workers indeed gain relatively more real authority if they are not monitored than if they are monitored. The reason is that in the former case they are much more likely to get their most preferred project than in the latter. This observation is robust even though uninformed managers do not always follow their informed workers recommendation under strong interest alignment, and even though informed managers do not always overrule their informed workers under weak interest alignment. We summarize our findings as follows.

Result 3 (Recommendation and Implementation) (a) Project implementation favors workers under weak interest alignment, whereas it favors managers under strong interest alignment. (b) Informed workers recommend their most preferred project. (c) If managers do not monitor, they follow informed workers' recommendations. If managers monitor, they overrule informed workers to implement their favorite project. (c) Whether information is hard or soft has no effect on the recommendation and implementation behavior.

\section{Discussion}

The above data analysis demonstrates that our empirical results are rather consistent with the theoretical predictions in the spirit of Aghion and Tirole (1997) and Baker, Gibbons, and Murphy (1999). The observed recommendation and implementation behavior suggests that abstaining from monitoring - and therefore strategic ignorance - serves as commitment device not to overrule workers. Workers seem to understand the strategic situation, such that monitoring discourages information gathering under weak interest alignment, whereas it has no substantial impact on information gathering under strong interest alignment. The finding that managers typically do not monitor under weak interest alignment suggests that they see the strategic commitment value of remaining uninformed. We consequently observe the non-monotonic pattern that monitoring is higher under strong than under full or weak interest alignment.

Yet two observations hint at the existence of substantial behavioral biases. First, monitoring rates are unusually frequent under full interest alignment with soft information. Second, monitoring encourages information gathering under full interest alignment if information is hard. In the following we relate these empirical results to control preferences and hidden benefits and costs of control. 


\subsection{Loss Aversion and Preferences for Control}

Consider first the high monitoring levels under full interest alignment with soft information. Our model with loss aversion implies that switching from hard to soft information increases monitoring incentives. But due to the endogeneity of the reference lottery, overall monitoring incentives also depend on the interest alignment. Under weak interest alignment the negative reference point effect discourages monitoring. Monitoring levels should be low with both hard and soft information. Under strong interest alignment the negative reference point effect can reduce the positive effect of going from hard to soft information. Under full interest alignment going from hard to soft information should increase monitoring rates, as there is no negative reference point effect. We observe exactly this pattern in our data. ${ }^{7}$

It is difficult to find convincing alternative explanation for the observed monitoring pattern. Whether information is hard or soft has no effect on recommendation, implementation, and information gathering behavior. This makes it unlikely that managers monitor more under soft information because they believe monetary gains from monitoring are higher with soft than with hard information. The observation that switching from hard to soft information increases monitoring rates rather suggest that managers might be driven by preferences for information. As summarized by Loewenstein (1994) there indeed exists a large psychological literature on curiosity. However, unless the underlying mechanism for curiosity is connected to disappointed expectations, and thus closely related to loss aversion, it is puzzling that less information triggers more monitoring only under full interest alignment. Individuals, moreover, learn at least the payoffs of the implemented project after each period. Managers might remain curious to find out what would have been the optimal project implementation decision - this is not revealed to them in case they do not monitor, workers recommend their preferred project, and managers do not by chance implement their most preferred project. Nevertheless, the provided feed-back should reduce curiosity. Overall, we therefore conclude that the observed monitoring patterns are not driven by preferences for information.

\footnotetext{
${ }^{7}$ See also the quantitative calculations in Table 2 . If $5 \%$ of workers are irrational, then predictions match the evidence if the parameter of loss aversion $\gamma$ equals 15.00 or 20.00 . If $10 \%$ of workers are irrational, then predictions match the evidence if the parameter of loss aversion $\gamma$ equals 10.00. Higher levels of loss aversion are not consistent with our evidence, since managers then have no incentives to monitor under strong interest alignment if information is hard.
} 
As an alternative explanation for excess centralization, Fehr, Herz, and Wilkening (2010) argue that in their experiment delegation and effort choices are driven by regret aversion. Regret averse individuals dislike to find out ex post that their ex-ante decisions have been wrong. ${ }^{8}$ In the context of our experiment this implies that managers suffer if they wrongly delegate decision to irrational workers who then take erroneous implementation decisions. Yet such models cannot explain excess monitoring under full interest alignment. The reason is that in this case regret averse managers regret wasting monitoring costs on rational workers who behave in the interest of managers anyway. Since most workers behave rationally, the control discouraging effect should dominate the control encouraging effect of regret aversion under full interest alignment. We therefore believe that control choices in our experiment are not driven by regret aversion.

Monitoring behavior also does not seem to be driven by pure preferences for control as found in Herz, Bartling, and Fehr (2011) and Owens, Grossman, and Fackler (2012). Such pure preferences for control create a tendency towards excess monitoring that does not depend on whether there is hard or soft information; this seems inconsistent with our evidence. To nevertheless further investigate pure preferences for control, we measure pure preferences for control directly. In a third part of the experiment, worker or manager again have to decide which project to implement. As before both worker and manager know the possible payoff combinations of the projects, but neither of the two know which payoff combination corresponds to which project. Payoff combinations remain the same as in the main part of the experiment, thus we have either full, strong, or weak interest alignment. However, managers and workers have no opportunity to collect any additional information on the investment projects at all. Whether workers or managers have the right to choose the project is determined via a first-price auction. First, both workers and managers simultaneously bid to buy the implementation decision right. Second, whoever makes the highest bid, has to pay his bid, but in turn acquires the right to decide which project is implemented. Ties are broken randomly. The third part contained five periods in which subjects played the bid for the right to choose game. We conjecture that individuals with pure preferences for control have incentives to acquire the objectively useless right to make the decision by bidding in the auction.

\footnotetext{
${ }^{8}$ For more details on formal definitions of regret aversion see Loomes and Sugden (1982), Filiz-Ozbay and Ozbay (2007), and Krähmer and Stone (forthcoming).
} 
We indeed find that in experimental points the average bid was 1.12 under full, 1.93 under strong, and 4.86 under weak interest alignment. The bidding difference between full and strong interest alignment is not significant ( $p$-value of 0.57 ), but there are significant bidding differences between weak interest alignment and the other two treatment variations ( $p$-values of 0.03). Since individuals might value the right to make decisions more in the presence of some conflict of interest, this could suggest that the bidding behavior reflects consistent preferences. The observation that some individuals pay for an objectively useless decision right - projects are always chosen in the dark - also suggests that individuals exhibit some pure preferences for control as argued by Herz, Bartling, and Fehr (2011) and Owens, Grossman, and Fackler (2012). However, bidding behavior is not consistently connected to delegation and monitoring decisions in the first two parts of the experiment. Overall, we consequently conclude that preferences for control as observed in our experimental setup are most likely to be driven by loss aversion.

\subsection{Hidden Benefits and Costs of Control}

Consider next our observation that under full interest alignment monitoring significantly increases information gathering when information is hard. This encouragement effect does not exist under strong interest alignment. This holds although monitoring should have no impact on information gathering in either treatment if individuals maximize expected payoffs. Our data therefore generate potentially interesting insights for the literature on the behavioral consequences of being monitored and being controlled. ${ }^{9}$

In the following we argue that this finding is consistent with cognitive evaluation theory. As summarized by Ryan and Deci (2000) cognitive evaluation theory argues that intrinsic motivation is enhanced by the satisfaction of two psychological needs: feelings of competence and autonomy. ${ }^{10}$ Studies suggest that exerting control via monitoring reduces performance by eroding feelings of autonomy. Although the focus is mostly on intrinsic motivation - doing something for its' own sake - Ryan and Deci (2000) argue that restricting autonomy can also reduce extrinsic motivation by affecting processes of internalization and integration.

\footnotetext{
${ }^{9}$ In addition to the extensive empirical literature already cited in the introduction, see also the theoretical contributions by Frey (1993), Bénabou and Tirole (2003), Sliwka (2007), Ellingsen and Johannesson (2008), Suvorov and van de Ven (2009), Herold (2010), and von Siemens (2011).

${ }^{10}$ Deci, Ryan, and Koester (1999) provide a meta-analytic review of the extensive empirical literature on intrinsic motivation and extrinsic rewards in social psychology. Plant and Ryan (1985) and Enzle and Anderson (1993) constitute typical examples for experimental studies in support of cognitive evaluation theory.
} 
A possible explanation for our finding - monitoring improves information gathering under full interest alignment - could be that under full interest alignment workers do not perceive being monitored as being controlled. Managers rather signal that they are willing to bear some costs to ensure that the mutually preferred project is chosen. Monitoring can then be seen as supportive, and thus increases motivation. ${ }^{11}$ When managers' preferences are not fully aligned with workers' preferences, monitoring provides managers with the opportunity to overrule workers. Being monitored - and the experience of being overruled - is interpreted as being controlled. This reduces worker motivation in line with the findings by Falk and Kosfeld (2006). We thus conclude that we find mild supportive evidence for the existence of hidden benefits and costs of control. ${ }^{12}$

\section{Conclusion}

This paper reports the results from a stylized laboratory experiment designed to test whether subjects use strategic ignorance to delegate real authority. We study a simple setup in which a worker can gather information on investment projects and recommend a project for implementation, while a manager finally makes the implementation decision. The manager can monitor the worker. For once this allows her to better exploit the information gathered by the worker. But monitoring also reduces the worker's incentives to gather information in the first place. Both these effects of monitoring are influenced by the interest alignment between manager and worker. Our data document a non-monotonic relationship between interest alignment and monitoring. This supports the key intuition of Aghion and Tirole (1997) that strategic ignorance can be an effective instrument to delegate real authority.

Although our results are largely in line with Aghion and Tirole (1997), some observations point at the existence of relevant behavioral biases. Most importantly, we observe frequent

\footnotetext{
${ }^{11}$ This is consistent with Ariely, Kamenica, and Prelec (2008). They find that manipulation of the perceived meaning of certain tasks affects performance.

${ }^{12}$ Note that under full interest alignment with hard information the information gathering rate of workers who are not monitored increases over time from 0.89 to 0.94 . At the same time the $p$-value for the difference in information gathering between workers who are monitored and workers who are not monitored increases from 0.04 to 0.09 . It could thus be that workers are learning to put in effort even when not monitored which would eliminate the encouragement effect of monitoring over time. This could also explain why we observe no significant difference in information gathering between workers who are monitored and workers who are not monitored under soft information. The reason is that subjects were exposed to soft information only after they could gather experience under hard information.
} 
monitoring even when interests between manager and worker are perfectly aligned, and this excess monitoring occurs more frequently if information on the worker's recommendation is limited rather than complete. Our favored explanation for these findings is that managers tend to be overly reluctant to delegate decision rights because of an exaggerated fear that in case of delegation things go wrong. We explore this explanation formally by introducing a small fraction of irrational workers and assuming that managers have reference dependent preferences as in Köszegi and Rabin (2006). The formal analysis shows that such loss aversion promotes keeping control when preferences are aligned. However, when interests between manager and worker are dispersed, loss aversion may actually diminish incentives to keep control. Moreover, reducing the manager's information on the worker's recommendation unambiguously strengthens monitoring incentives of loss averse managers. These predictions are supported by our experimental findings.

What can we learn from our results about manager-employee relations in practice? In our laboratory experiment we study the behavior of inexperienced subjects in a highly stylized situation representing one of the simplest organizational settings. Real organizations are more complex, their members are typically experienced, interact repeatedly and personally, and self-select to join the organization. Our experiment is thus likely to ignore a variety of aspects that may be important drivers of delegation behavior in the field. But only by abstracting from confounding elements an experiment can be well-suited to test the basic behavioral forces that underly a particular theoretical mechanism like Aghion and Tirole (1997). ${ }^{13}$ In support of their theory we find that managers in our experiment make use of strategic ignorance to credibly delegate real authority, and that changes in interest alignment have by and large the predicted impact on monitoring.

However, the observation that subjects in some situations systematically deviate from strictly following monetary incentives points at systematic behavioral biases. Our data suggests that excess monitoring is driven by managers' loss aversion together with an irrational fear that workers may mess up. Both these components have received support elsewhere. Following

\footnotetext{
${ }^{13}$ Camerer and Weber (forthcoming, p.3) note that "... the presumption in economic theory is that basic principles apply widely unless the theory explicitly contains variables that parameterize boundaries of likely empirical applicability." They continue to observe that "If obvious distinctions between large firms and small experiments, like incentives or experience and selection of agents, are expected to make a difference in behavior, then the way in which those distinctions matter should be part of the theory." There are no components in the theory of Aghion and Tirole that explicitly suggest that their argument cannot be investigated in a simplifying laboratory experiment.
} 
the seminal contributions by Kahneman and Tversky (1979) and Kahneman and Tversky (1984), numerous empirical studies argue that many individuals are loss averse. Devers, Wiseman, and Holmes (2007) and more recently Dittmann, Maug, and Spalt (2010) suggest that managers are no exception. Our second assumption, the irrational fear that workers might misbehave, could find its origin in various established cognitive biases. For example, Kahneman (2011) argues that managers may both overestimate and overweight the probability of rare events in their delegation decision. Pfeffer, Cialdini, Hanna, and Knopoff (1998) obtain experimental evidence that when managers are lead to believe that they are more involved in controlling the work process, their perception of the final result is biased upwards. They ascribe this finding to a combination of faith in supervision and self-enhancement bias: managers in fact perceive a work outcome produced under their supervision as superior to an identical outcome realized without it. Our conjecture that delegation choices might be driven by an irrational fear that subordinates might make mistakes is thus consistent not only with our experimental evidence.

The presence of the conjectured behavioral preferences could have important consequences for organizational design. Camerer and Malmendier (2007) argue that organizational outcomes could benefit a lot if organizations were able to curtail, repair, or play on members' behavioral biases. As an example consider the rise and decline of the famous Oticon spaghetti organization as discussed in detail in the case study by Foss (2003). Oticon tried to spur innovation by decentralizing decision rights. But they allowed executives to keep effective control, since all decisions by subordinates had to be approved by a supervision committee. Executives turned out to be overly inclined to meddle in subordinates' decision making. This lead to reduced employee motivation and low levels of innovation. Our experiment suggests that loss aversion and an irrational fear of worker misdemeanor might have spurred excess monitoring and control by executives. Taking this into account - for example by facilitating the use of strategic ignorance as delegation device while reducing the temptation to exert control - might have improved organizational outcomes. ${ }^{14}$

\footnotetext{
${ }^{14}$ Among other organizational and contractual changes, the introduction of the decentralized spaghetti organizational structure was accompanied by moving into a new building. To symbolize flat hierarchies all desks were placed in open office spaces, where subordinates could change workplaces depending on their chosen team participation. All activities of subordinates thus happened under the eyes of the executives. Information technology systems were adjusted to give everybody access to all available information. One might therefore argue that Oticon chose organizational measures that minimize the scope for strategic ignorance, while executives were constantly tempted to check that subordinates make no mistakes.
} 
We end with some suggestions for future research. First, it would be insightful to enrich our experimental design to fruitfully investigate the prediction that loss aversion may diminish incentives to control. Finding out more precisely what drives preferences for control could have important consequences for organizational design. Second, in our setup managers can perfectly commit ex ante not to monitor ex post. Yet in practice this may not be that easy: in the case study from Oticon this was almost made impossible since subordinates' decisions had to be approved by the supervisory committee. Following Foss, Foss, and Vázquez (2006) it would therefore be interesting to investigate whether such strong commitment is indeed essential, and what type of organizational practices would work to credibly provide it. 


\section{References}

Aghion, P., And J. Tirole (1997): "Formal and Real Authority in Organizations," Journal of Political Economy, 105(1), 1-29.

Ariely, D., E. Kamenica, and D. Prelec (2008): "Man's Search for Meaning: The Case of Legos," Journal of Economic Behavior and Organization, 67(3-4), 671-677.

Baker, G., R. Gibbons, and K. J. Murphy (1999): "Informal Authority in Organizations," Journal of Law, Economics, and Organization, 15, 56-73.

Barkema, H. G. (1995): "Do Top Managers Work Harder When They Are Monitored?," Kyklos, 48, 19-42.

BÉnabou, R., And J. Tirole (2003): "Intrinsic and Extrinsic Motivation," Review of Economic Studies, 70, 489-520.

Camerer, C., G. Loewenstein, and M. Weber (1989): "The Curse of Knowledge in Economic Settings: An Experimental Analysis," Journal of Political Economy, 97(5), pp. $1232-1254$.

Camerer, C., and U. Malmendier (2007): Behavioral Economics of Organization, in Behavioral Economics and Its ApplicationsPrinceton University Press.

Camerer, C. F., and R. A. Weber (forthcoming): Experimental Organizational Economics, in The Handbook of Organizational EconomicsPrinceton University Press.

Dana, J., R. A. Weber, and J. X. Kuang (2007): "Exploiting moral wiggle room: experiments demonstrating an illusory preference for fairness," Economic Theory, 33(1), pp. $67-80$.

Deci, E. L., R. M. Ryan, and R. Koester (1999): "A Meta-Analytic Review of Experiment Examining the Effects of Extrinsic Reward on Intrinsic Motivation," Psychological Bulletin, 125(6), 627-668.

Devers, C. E., R. M. Wiseman, and R. M. Holmes (2007): "The Effects of Endowment and Loss Aversion in Managerial Stock Option Valuation," Academy of Management Journal, 50(1), 191-208. 
Dickinson, D., And M.-C. Villeval (2008): "Does Monitoring Decrease Work Effort? The Complementarity between Agency and Crowding-Out Theories," Games and Economic Behavior, 63, 56-76.

Dittmann, I., E. Maug, and O. Spalt (2010): "Sticks or Carrots? Optimal CEO Compensation when Managers Are Loss Averse," The Journal of Finance, 65(6), 2015-2050.

Ellingsen, T., and M. Johannesson (2008): "Pride and Prejudice: The Human Side of Incentive Theory," American Economic Review, 98(3), 990-1008.

Enzle, M. E., And S. C. Anderson (1993): "Surveillant Intentions and Intrinsic Motivation," Journal of Personality and Social Psychology, 64(2), 257-266.

Falk, A., And M. Kosfeld (2006): "The Hidden Costs of Control," American Economic Review, 96(5), 1611-1630.

Fehr, E., H. Herz, and T. Wilkening (2010): "The Lure of Authority: Delegation and Incentives in Organizations," mimeo, University of Zurich.

Feldman, M. S., And J. G. March (1981): "Information in Organizations as Signal and Symbol," Administrative Science Quarterly, 26(2), pp. 171-186.

Filiz-Ozbay, E., and E. Y. Ozbay (2007): "Auctions with Anticipated Regret: Theory and Experiment," The American Economic Review, 97(4), pp. 1407-1418.

Fischbacher, U. (2007): "z-Tree: Zurich Toolbox for Ready-made Economic Experiments," Experimental Economics, 10(2), 171-78.

Foss, K., N. J. Foss, And X. H. VÁzquez (2006): "Tying the Manager's Hands: Constraining Opportunistic Managerial Intervention," Cambridge Journal of Economics, 30, $797-818$.

Foss, N. J. (2003): "Selective Intervention and Internal Hybrids: Interpreting and Learning from the Rise and Decline of the Oticon Spaghetti Organization," Organization Science, 14(3), 331-349.

Frey, B. S. (1993): "Does Monitoring Increase Work Effort? The Rivalry with Trust and Loyalty," Economic Inquiry, 31(4), 663-670.

Frey, B. S., And R. Jegen (2001): "Motivation Crowding Theory," Journal of Economic Surveys, 15(5), 589-611. 
Grossman, Z. (2010): "Strategic Ignorance and the Robustness of Social Preferences," mimeo, UC Santa Barbara.

Herold, F. (2010): "Contractual Incompleteness as a Signal of Trust," Games and Economic Behavior, 68, 180-191.

Herz, H., B. Bartling, And E. Fehr (2011): "The Value of Authority," mimeo, University of Zurich.

Herzberg, F. (2003): "One More Time: How Do You Motivate Employees?," Harvard Business Review, 81(1), 87-96.

Kahneman, D. (2011): Thinking Fast and Slow. Farrar, Strauss, Giroux, New York.

Kahneman, D., And A. Tversky (1979): "Prospect Theory: An Analysis of Decision under Risk," Econometrica, 47(2), pp. 263-292.

- (1984): "Choices, Values, and Frames," American Psychologist, 39(4), 341-350.

Köszegi, B., And M. Rabin (2006): "A Model of Reference-Dependent Preferences," Quarterly Journal of Economics, 121(4), 1133-1165.

KrähmeR, D., And R. Stone (forthcoming): "Anticipated Regret as an Explanation of Uncertainty Aversion," Economic Theory.

LAI, E. K., AND W. Lim (2012): "Authority and communication in the laboratory," Games and Economic Behavior, 74(2), 541 - 560 .

Loewenstein, G. (1994): "The Psychology of Curiosity: A Review and Reinterpretation," Psychological Bulletin, 116(1), 75-98.

Loewenstein, G., D. A. Moore, and R. A. Weber (2006): "Misperceiving the Value of Information in Predicting the Performance of Others," Experimental Economics, 9, 281295.

Loomes, G., and R. Sugden (1982): "Regret Theory: An Alternative Theory of Rational Choice Under Uncertainty," The Economic Journal, 92(368), pp. 805-824.

Manzoni, J.-F., And J.-L. Barsoux (1998): "The Set-Up-to-Fail Syndrom: How Bosses Create Their Own Poor Performers," Harvard Business Review, 76(2), 101-113. 
Owens, D., Z. Grossman, and R. Fackler (2012): "The Control Premium: A Preference for Payoff Autonomy," mimeo, UC Santa Barbara.

Pfeffer, J., R. B. Cialdini, B. Hanna, and K. Knopoff (1998): "Faith in Supervision and the Self-Enhancement Bias: Two Psychological Reasons Why Managers Don't Empower Workers," Basic and Applied Social Psychology, 20(4), 313-321.

Plant, R. W., and R. M. Ryan (1985): "Intrinsic Motivation and the Effects of SelfConsciousness, Self-Awareness, and Ego-Involvement: An Investigation of Internally Controlling States," Journal of Personality, 53(3), 435-449.

Poulsen, A. U., And M. W. M. Roos (2010): "Do People Make Strategic Commitments? Experimental Evidence on Strategic Information Avoidance," Experimental Economics, $13(2), 206-225$.

Poulsen, A. U., And J. H. W. TAN (2007): "Information Acquisition in the Ultimatum Game: An Experimental Study," Experimental Economics, 10(4), 391-409.

Ryan, R. M., and E. L. Deci (2000): "Self-Determination Theory and the Facilitation of Intrinsic Motivation, Social Development, and Well-Being," American Psychologist, 55(1), $68-78$.

SliwkA, D. (2007): "Trust as a Signal of a Social Norm and the Hidden Costs of Incentive Schemes," American Economic Review, 97(3), 999-1012.

Suvorov, A., And J. VAn de Ven (2009): "Discretionary Rewards as Feedback Mechanism," Games and Economic Behavior, 67, 665-681.

von Siemens, F. A. (2011): "Intention-Based Reciprocity and the Hidden Costs of Control," Tinbergen Institute Discussion Paper 11-115/1.

Williamson, O. E. (1996): The Mechanisms of Governance. Oxford University Press, Oxford, U.K. 


\section{Appendix A: Theoretical Analysis Loss Aversion}

In this section we provide all technical details concerning our analysis of loss aversion. We start with the baseline case with hard information. We first look at managers implementation decisions. For most situations results are clear. Managers make a random implementation decision in case worker did not gather information. Managers implement their preferred project in case they monitor their workers and workers gather information. The reason is that this maximizes managers' payoffs and thereby also eliminates any potential suffering from loss aversion. We next focus on the more interesting case in which managers do not monitor and workers gather information. We conclude with assessing the impact of soft information on the monitoring incentives of loss averse managers.

\section{Uninformed Managers Follow Informed Recommendation}

We show that for arbitrary reference lotteries loss-averse and uninformed managers follow the recommendation of informed workers who recommend the project that is best for workers. Fix an arbitrary reference lottery according to which the manager expects to get payoff $m_{l} \in \mathcal{M}$ with probability $\tilde{q}\left(m_{l}\right)$. Suppose the worker recommends a project with payoff $m_{k} \in \mathcal{M}$. The manager observes this but no other payoff of any alternative project. It is then optimal to follow the worker's recommendation if and only if

$$
\begin{aligned}
& m_{k}-\gamma \sum_{l \in \mathcal{K}} \max \left\{m_{l}-\right.\left.m_{k}, 0\right\} \tilde{q}\left(m_{l}\right) \geq \\
& \frac{1}{K-1} \sum_{j \in \mathcal{K} \backslash\{k\}}\left(m_{j}-\gamma \sum_{l \in \mathcal{K}} \max \left\{m_{l}-m_{j}, 0\right\} \tilde{q}\left(m_{l}\right)\right)
\end{aligned}
$$

which we can rewrite as

$$
\begin{aligned}
& m_{k}-\frac{1}{K-1} \sum_{j \in \mathcal{K} \backslash\{k\}} m_{j} \geq \\
& \quad \gamma \sum_{l \in \mathcal{K}}\left(\max \left\{m_{l}-m_{k}, 0\right\}-\frac{1}{K-1} \sum_{j \in \mathcal{K} \backslash\{k\}} \max \left\{m_{l}-m_{j}, 0\right\}\right) \tilde{q}\left(m_{l}\right)
\end{aligned}
$$

For $m_{k}=m_{w}$ the left hand side of inequality (14) is strictly larger than zero by (4) since by assumption implementing the project that is best for the worker yields the manager a higher expected payoff than randomly implementing an alternative project.

We next show that (4) also implies that the right hand side of inequality (14) is weakly negative for $m_{k}=m_{w}$. We demonstrate this by showing that the terms in the big brackets 
are weakly negative for all $m_{l} \in \mathcal{M}$. This holds directly for all $m_{l} \in \mathcal{M}$ with $m_{l} \leq m_{k}$ since then the first maximum function is zero whereas the second sum of maximum functions is by construction weakly positive. For any $m_{l} \in \mathcal{M}$ with $m_{l}>m_{k}$ we have

$$
\begin{gathered}
m_{l}-m_{k}-\frac{1}{K-1} \sum_{j \in \mathcal{K} \backslash\{k\}} \max \left\{m_{l}-m_{j}, 0\right\} \leq \\
m_{l}-m_{k}-\frac{1}{K-1} \sum_{j \in \mathcal{K} \backslash\{k\}}\left(m_{l}-m_{j}\right)= \\
m_{l}-m_{k}-m_{l}+\frac{1}{K-1} \sum_{j \in \mathcal{K} \backslash\{k\}} m_{j} .
\end{gathered}
$$

For $m_{k}=m_{w}$ this expression is strictly smaller than zero by (4). Since the above argument holds for all $m_{l}$ it also holds for the expected value.

Intuitively it is optimal for loss averse managers to follow the recommendation for two reasons. First, it maximizes expected payoffs by assumption. Second, loss aversion makes managers in some sense risk averse, and implementing an unknown alternative project is more risky than following the recommendation. Loss aversion thus increases the real authority that informed workers hold when managers do not monitor, because loss averse managers might be willing to follow recommendations even if this does not maximize their expected payoff. In our setup this extra authority is irrelevant since informed workers can push through their most preferred project when managers do not monitor and maximize expected payoffs.

\section{Loss Aversion and Incentives to Monitor}

Workers thus know that they get their most preferred project if they gather information and managers do not monitor, and that they get the project most preferred by managers if they gather information and managers do monitor. Workers' incentives to gather information are not affected by managers' loss aversion. In the following we derive the incentives for loss averse managers to monitor.

Suppose managers do not monitor. Workers who behave rationally then gather information and push through their most preferred project. Only rational worker behavior determines the reference lottery, which is thus getting $m_{w}$ with probability one. Suppose an informed worker recommends a project that yields the manager payoff $m_{k}$. The managers realizes that the worker is irrational whenever $m_{k} \neq m_{w}$. The recommendation then reveals no information on 
the projects other than revealing the payoffs of the recommended project. We can therefore define

$$
A\left(m_{k}, \gamma\right):=m_{k}-\gamma \max \left\{m_{w}-m_{k}, 0\right\}
$$

and

$$
R\left(m_{k}, \gamma\right):=\frac{1}{K-1} \sum_{j \in \mathcal{K} \backslash\{k\}}\left(m_{j}-\gamma \max \left\{m_{w}-m_{j}, 0\right\}\right)
$$

as the expected utility of the manager as she follows or rejects the recommendation. Using her available information in her implementation decision, she maximizes her expected utility to get $\max \left\{A\left(m_{k}, \gamma\right), R\left(m_{k}, \gamma\right)\right\}$.

Managers who do not monitor consequently receive as expected utility

$$
(1-\pi) m_{w}+\frac{\pi}{2 K} \sum_{k \in \mathcal{K}} \max \left\{A\left(m_{k}, \gamma\right), R\left(m_{k}, \gamma\right)\right\}+\frac{\pi}{2 K} \sum_{k \in \mathcal{K}} A\left(m_{k}, \gamma\right)
$$

The first term is the expected payoff if the worker behaves rationally. The second term is the expected payoff if the worker does not behave rationally because he gathers information but then recommends a randomly determined project. The third term is the expected payoff if the worker does not behave rationally as he does not gather information.

In the following we describe the expected payoff if the manager monitors the worker. We distinguish two cases. First, suppose monitoring does not discourage information gathering by workers who behave rationally. The reference lottery is getting $m_{m}$ with probability one. Managers who monitor then receive as expected utility

$$
(1-\pi) m_{m}+\frac{\pi}{2} m_{m}+\frac{\pi}{2 K} \sum_{k \in \mathcal{K}}\left(m_{k}-\gamma\left(m_{m}-m_{k}\right)\right)-\phi .
$$

The first term is the expected payoff if the worker behaves rationally. The second term is the expected payoff if the worker does not behave rationally because he gathers information but then recommends a randomly determined project. The manager then learns the state of the world by monitoring. She can thus always implement her preferred project. The third term is the expected payoff if the worker does not behave rationally because he gathers no information. The last term are the monitoring costs.

Second, suppose monitoring does discourage information gathering by workers who behave rationally. The reference lottery follows from a random project choice. Managers who monitor 
receive as expected utility

$$
\begin{aligned}
\frac{1-\pi}{K} \sum_{k \in \mathcal{K}}\left(m_{k}-\gamma \sum_{l \in \mathcal{K}} \max \{\right. & \left.\left.m_{l}-m_{k}, 0\right\}\right)+\frac{\pi}{2} m_{m} \\
& +\frac{\pi}{2 K} \sum_{k \in \mathcal{K}}\left(m_{k}-\gamma \sum_{l \in \mathcal{K}} \max \left\{m_{l}-m_{k}, 0\right\}\right)-\phi .
\end{aligned}
$$

The interpretation of the above terms equals the interpretation of (21). The only difference is that the reference lottery is no longer degenerate. This imposes an utility loss on loss averse managers even if workers behave rationally. The incentives to monitor for loss averse managers are given by deducting (20) from (21) or (22).

\section{Soft versus Hard Information}

We finally investigate the case in which an uninformed manager does not learn the payoffs of the recommendation of an informed worker. Suppose rational workers propose their preferred project. A loss averse manager follows the recommendation given any reference lottery for the following reason. The manager cannot observe whether the recommendation is made from a worker who behaves rationally or a worker who does not behave rationally. With probability $\pi$ the recommendation is random since the worker behaves irrationally. Following the recommendation then gives the same expected utility as implementing any other project. With probability $1-\pi$ the recommendation yields payoff $m_{w}$ because the worker behaves rationally. By the same argument as with hard information it is then optimal to implement the recommended project. Since it is optimal to follow the recommendation in both cases, a loss averse manager optimally implements the recommended project in case workers who behave rationally always recommend their most preferred project.

We can now investigate monitoring incentives. There is no difference between hard and soft information in case the manager monitors. The impact of soft information on monitoring incentives therefore is the same no matter whether monitoring encourages or discourages monitoring. We thus focus on the case in which the manager does not monitor. Workers who behave rationally then gather information and recommend their most preferred project which the manager implements. The reference lottery is thus getting $m_{w}$ with probability one. The expected utility of the manager is then

$$
(1-\pi) m_{w}+\frac{\pi}{K} \sum_{k \in \mathcal{K}} A\left(m_{k}, \gamma\right)
$$

The first term is the expected payoff in case the worker behaves rationally. The second term is the expected payoff in case the worker behaves irrationally. In that case the manager 
essentially implements a random project. The impact of soft information on the monitoring incentives of loss averse managers follows from comparing (23) from (20). 


\section{Monitoring Your Friends, Not Your Foes:}

\section{Strategic Ignorance And The Delegation Of Real Authority}

By

Silvia Dominguez-Martinez and Randolph Sloof and Ferdinand A. von Siemens

\section{General Remarks}

The instructions for all three treatments were identical except for the payoff combinations of the three investment projects. These sample instructions are from the treatment with strong interest alignment. The current general remarks and the title were, of course, not included in the instructions for the experimental subjects. Instructions for the different parts of the experiment were handed out separately, and only after all subjects had completed the previous part or parts. Part 4 was a questionnaire including a short version of the big five personality test.

\section{Instructions}

\section{General Information}

Thank you for participating in this experiment. The amount of money you earn depends upon the decisions you and the other participants make. Your earnings are given in points. The experiment consists of four parts. Your overall earnings equal the sum of your points in each part. The conversion rate is 150 points for 1 euro. We will pay out your overall earnings in cash after you have completed the entire experiment and filled out a final questionnaire. We ensure that your final earnings remain confidential: no other participant from the experiment will learn your final earnings.

There are two types of participants: managers and workers. One half of the participants will be managers, and the remaining half will be workers. You will be randomly assigned one of these roles. Which role you have, you will learn at the start of the experiment. Your role will not change during the experiment.

The experiment consists of four parts. This sheet contains the instructions for part one. Instructions for the next part follow after this part has been completed (and so on). Please do not communicate with other participants during the experiment. If you have a question, please raise your hand. The experimenter will then come to your table to answer your question in private.

\section{Part 1 of the Experiment}

\section{General information}

The first part of the experiment consists of 20 project implementation decisions. For each project implementation decision, one manager and one worker are randomly paired. You are never paired 
with the same other participant twice in a row. You cannot predict when you will be paired with the same other participant again.

In every project implementation decision, manager and worker face three projects $(\mathbf{A}, \mathbf{B}, \mathbf{C})$ that can be implemented. These projects differ in the points that they yield manager and worker upon implementation. Three payoff combinations are possible. One project yields 80 points to manager and 100 points to worker, one project yields 100 points to manager and 80 points to worker and one project yields 15 points to manager and 15 points to worker. The problem is that manager and worker do not a priori know which payoff combination corresponds to which project.. Each period the payoff combinations are randomly assigned to project A, B and C. Thus over the periods project A corresponds to different payoff combinations etc.

Before the manager finally decides which project to implement (either A, B, or C), the worker can decide whether to gather information on the payoffs of the projects or not, and the manager can decide whether to monitor the worker's information gathering or not. Gathering information on the projects costs the worker 10 points. Monitoring the worker costs the manager 10 points.

\section{Sequence of Actions}

The precise timing of the decisions and the resulting distribution of information that follows from these decisions are as follows. There are four phases.

\section{Phase 1}

The manager chooses between Monitoring the worker and Not Monitoring the worker. Monitoring the worker costs the manager 10 points.

\section{Phase 2}

The worker observes the manager's choice. He then chooses between Information and No Information. Information costs the worker 10 points.

Depending on the worker's information gathering decision, he may or may not learn the characteristics of the three projects.

- If the worker has chosen Information, the payoff characteristics of all three projects (A, B, and C) are revealed to him.

- If the worker has chosen No Information, no information about the projects is revealed to him.

\section{Phase 3}

The worker proposes a project to the manager, either A, B, or C.

The manager observes which project the worker has proposed.

Depending on the manager's and the worker's earlier decisions, additional information may be revealed to the manager.

- If the worker has chosen No Information, no information about the projects is revealed.

- If the worker has chosen Information and the manager has chosen No Monitoring, the manager learns the payoff characteristics of the proposed project only.

- If the worker has chosen Information and the manager has chosen Monitoring, the manager learns the payoff characteristics of all three projects. 


\section{Phase 4}

The manager finally decides which project to implement, either A, B, or C.

\section{Payoff}

The number of points earned by manager and worker respectively are their points from the implemented project minus their respective costs of the monitoring decision (either 10 or 0 points) and the information gathering decision (either 10 or 0 points).

The three possible payoff combinations of the projects are summarized in the table below

\begin{tabular}{|l|c|c|c|}
\hline & $(100,80)$ & $(80,100)$ & $(15,15)$ \\
\hline Manager & 100 & 80 & 15 \\
\hline Worker & 80 & 100 & 15 \\
\hline
\end{tabular}

Your overall payoff from part 1 of the experiment is the sum of points earned in the 20 project implementation decisions.

\section{Part 2 of the Experiment}

The second part of the experiment consists of 10 project implementation decisions. As compared to part 1 the main difference is the amount of information that is revealed to the manager after the worker has gathered information and proposed a project. In this part, if the manager does not monitor the worker, he never learns anything about the payoff characteristics of the projects. In particular, this means that he also does not learn the characteristics of the project proposed by the worker. If the manager monitors the worker, he learns the payoff characteristics of all three projects if the worker chooses to gather information.

The remainder of part 2 is identical to part 1 . This means that for each project implementation decision you will be randomly paired with another participant. Again you are never paired with the same other participant twice in a row. You cannot predict when you will be paired with the same other participant again. You keep the same role as in part 1 of the experiment.

Like in part 1 , the manager can decide whether to monitor the worker or not. Monitoring the worker costs the manager 10 points. Then the worker observes the manager's choice and can decide whether to learn the payoff characteristics of the projects (A, B, or C) or not. Gathering information on the projects costs the worker 10 points. After that the worker proposes a project to the manager (either A, B, or C). Finally, the manager decides which project to implement. The three possible payoff combinations of the projects are just as before:

\begin{tabular}{|l|c|c|c|}
\hline & $(100,80)$ & $(80,100)$ & $(15,15)$ \\
\hline Manager & 100 & 80 & 15 \\
\hline Worker & 80 & 100 & 15 \\
\hline
\end{tabular}


The number of points earned by manager and worker respectively are their points from the implemented project minus their respective costs of the monitoring decision (either 10 or 0 points) and the information gathering decision (either 10 or 0 points). Your overall payoff from part 2 of the experiment is the sum of points earned in the 10 project implementation decisions. The overall payoff from part 2 is added to the overall payoff of part 1.

\section{Part 3 of the Experiment}

The third part of the experiment consists of 5 project implementation decisions. In every project implementation decision, manager and worker face three projects $(\mathbf{A}, \mathbf{B}, \mathbf{C})$ that can be implemented. These projects differ in the points that they yield manager and worker upon implementation. As in the previous parts three payoff combinations are possible. One project yields 100 to manager and 80 to worker, one project yields 80 to manager and 100 to worker and one project yields 15 to manager and 15 to worker. Both the manager and the worker do not know which payoff combination corresponds to which project and cannot obtain additional information about this.

What also differs from the previous parts of the experiment is that an auction between the worker and the manager determines who has the right to choose which project is implemented. Both worker and manager simultaneously make a bid to buy the implementation decision right. The bid has to be an integer $(0,1,2,3, \ldots$ etc); it cannot exceed 120 . Whoever has made the highest bid, decides which project is implemented. If both manager and worker make the same bid, the decision right is randomly assigned to either the manager or the worker, with equal probability. Note that the decision maker chooses the project (either A, B, or C) without knowing which payoff combination corresponds to which project. After the project implementation decision has been made, manager and worker learn the payoffs of the project that will be implemented and observe the highest bid made for the decision right.

The number of points earned by the decision maker are the points from the implemented project minus his bid. The other participant simply gets his points from the implemented project. Your overall payoff from part 3 of the experiment is the sum of points earned in the 5 project implementation decisions. The overall payoff from part 3 is added to the overall payoff of part 1 and part 2. 